\title{
Mathematical Modeling for Measures of Supply Chain Flexibility
}

\author{
G. M. G. Farok \\ York University, Toronto, Canada
}

\begin{abstract}
Supply chain flexibility is a competitive measure of supply chain aspects. It is a linkage medium between supply chain players and business performance. It absorbs the change in market conditions, demand volume and mix, product differentiations, commodity prices, availability of technology, labor costs, and exchange rates, utilization of equipment, production and logistics environment, cultural issues or any disruption in supply chain elements. This conception can be used as flexible guide that develop very well for multistage supply chains and it is established a model to meet the balancing situation of supply chain flexibilities by adjusting weight and individual probabilities. These results would lead to support and accommodate the managerial decisions as well as global supply chain management strategy.
\end{abstract}

Key Words: Supply, Flexibility, Measures, Management, Links

\section{INTRODUCTION}

Supply Chain Management (SCM) is an integration of business relationships among the elements: original supplier to end user to meet customer requirements. Nowadays, competition has been shifted from the individual company to the supply chain element as an effective adjustment of supply chain uncertainties. Competition is seen as a way of gaining competitive advantage for all companies in the business. Flexibility is an ability to change or respond to environmental uncertainty with little penalty in time, effort, cost and performance. In addition, competitive environment markets are becoming more international, dynamic, and customer-driven. Customers are demanding more variety, better quality and service, including both reliability and faster delivery. With increased global competition, buyers became more sophisticated, demanding more customization and shorter product life cycles. Firms are concentrated on the reduction of cycle time and solving the tradeoffs between efficiency and flexibility. It is also recognized the necessity of looking beyond the borders of their own firm to their suppliers to suppliers and customers to customers ${ }^{1}$.

It is defined adaptive behavior as -"the mechanism for assessing the current state of its external domain and incorporated this into its 'decision' about future action in order to maintain autonomous and reasoning capabilities" ${ }^{\prime 5}$. When the supply chain suffers from uncertainties in demand and supply capacity, this mechanism can provide elasticity for both supplier and buyer to adjust the final quantity to be supplied/ordered, and the production quantity to be produced respectively. This flexibility, therefore, improving their performance as well as cost saving. This strategy is effective for distributing of multi-product manufacturing supply chain networks which is subject to uncertainties in customer demand; i.e. supplier capacity and also supplier's capacity utilization. To remain competitive with multiproduct environment, organizations must be able to move fast and quickly adapt to change and to reconfigure their key business processes with changing market conditions ${ }^{6}$.

\section{FEATURES OF FLEXIBILITY}

Flexibility in supply chains may consider a potential resource to improve the company's efficiency and a significant measure of supply chain performance. Supply chain flexibility is defined to include those flexibility parameters that directly impact a firm's customers and are the shared responsibility of two or more functions along the supply chain, whether internal (like manufacturing) or external (like suppliers) to the firm $^{2}$. Today supply chain demands a flexible supply relationship between buyer and seller. The demand for the end product is highly uncertain in many cases. In such situations the buyer may prefer to use supply flexibility, as opposed to an inventory holding strategy, to counter the demand drop. Companies that had maintained strong supply chain networks found that they were unable to stop the supply process as demand fell below threshold levels. The need to accommodate uncertainty in the supply process raises the issue of flexibility. It is really impossible for a buyer to predict downstream conditions, he may often issue procurement orders those are for a smaller quantity than normal or request a shorter supply lead-time than normal. In an inflexible relationship, a supplier will only accept those orders at a much higher unit price [3]. It is more difficult to make global optimization and supply chains need to be designed for, and operated in, uncertain environments. Uncertainty of product demand leads to component demand uncertainty, which requires a flexible supply chain relationship. The less flexible the relationship, the more likely the buyer will face cost penalties when demand conditions change. In general, cost, quality, delivery and flexibility are the important components for decision making about the supplier 
selections ${ }^{4}$. There are six major types of supply chain risks: Supply risks, process risks, demand risks, intellectual property risks, behavioral risks, political/ social risks. On the other hand, supply reliability, supply quality, supplier solvency, supply base reduction are considered as other types of supply risks. Mitigating supply chain risks involve designing a process so that any deviation to perfection will be identified and corrective action will be taken immediately. Lower level flexibility is a risk reduction tool which introduces coordination strategy with supply chain initiatives, i.e. more product variety, more frequent new product introductions, more sales channels/ markets, online sourcing including e-markets and online auctions, offshore manufacturing, just in time inventory systems, vendor managed inventory, outsourcing manufacturing, information technology and logistics. Supply chain initiatives can improve financial performance and can be effective to overcome supply chain risks in a stable environment ${ }^{7,8}$. Flexibility is implemented in order to develop competitiveness in a changing environment ${ }^{21}$.

\section{Application of flexibility in supply Contract}

Usually supply contract is the key document which defines the parameters within which the two parties are working with each other. This is a legal binding document, which is setup to protect the parties in case of disagreement. The supply contract should be negotiated at the beginning of the relationship and must be strong enough to be applicable in all expected demand-supply scenarios. Researchers introduced three parameters, based on which the supply contract established $^{3,9}$.There has an important buyer-supplier contractual relationship. This relationship implies supplier to buyer in a fixed period replenishment orders (order shipments) with demand uncertainty.

\section{Literature review on SC flexibility modeling:}

1.Dynamic business environment ${ }^{1}$ :

Useful criteria: It is convenient for logistics operations, a physical structure, processes and its activities as well as the information systems needed for design, operations, planning and reporting.

Modeling approach: Theoretical approach in terms of profitability and growth, seem to be found among companies with the highest dynamic capabilities.

2. SC performance measurement system ${ }^{3}$ :

Useful criteria: Three components: resource, output and flexibility.

Modeling approach: Mathematical model for volume flexibility, delivery flexibility, mix flexibility and new product flexibility.

3.Product life cycles and complex corporate joint ventures ${ }^{15}$ :
Useful Criteria: It is considered the complete scope of SCM from supplier of raw materials, through factories and warehouses to figure out the demand in a store for a finished product.

Modeling approach: This is a theoretical approach related to the performance of suppliers, the reliability of manufacturing and transportation processes and changing customer desires.

4.Manufacturing flexibility ${ }^{17}$ :

Useful criteria: Manufacturing schedule fluctuations, JIT purchasing, manufacturer slack capacity, low levels of parts commonality, demand volatility and forecast accuracy.

Modeling approach: An exploratory study and subjectivity analysis with questionable generality of the results.

5. Intra-firm flexibility ${ }^{42}$ :

Useful criteria: This is effective for cross-enterprise nature of supply chain flexibility and the need to improve flexibility measures across firms.

Modeling approach: It builds on theoretical foundation and leads to more effective application of SC strategies. 6.Flexibility related to machine, process, routing, part, worker and the like are all associated with production system $^{48}$ :

Useful criteria: To identify major determinant of competitiveness in an increasingly intense competition in the market place.

Modeling approach: Mathematical model for product delivery system flexibility, production system flexibility, product development flexibility and supply system flexibility.

7.Manufacturing flexibility ${ }^{54}$ :

Useful criteria: It is an important research flexibility area construct for meeting customer demand.

Modeling approach: An Internet-based Delphi study; where expert opinion is considered the best evidence.

8.The robustness of the buyer-supplier relationship ${ }^{55}$ :

Useful criteria: It is a measure for estimating supply chain flexibility as a function of varying supply lead times and order quantities.

Modeling approach: Mathematical model is able to estimate the annual procurement, price and penalties under different supply conditions.

9.Product architecture and design ${ }^{59}$ :

Useful criteria: It depends on design costs, bargaining power, technical coordination costs, scale of the market, customer's taste for performance and nature of technology.

Modeling approach: Mathematical model is developed to explain the inter-relationship between SC configuration and its degree of modularity.

10. Highly cyclical furniture industries ${ }^{60}$ :

Useful criteria: SC flexibility with environmental uncertainty, business performance and functional interfaces. 
Modeling approach: This model is an empirical study with respect to volume, launch and target market flexibilities.

11.To measure machine and routing flexibilities ${ }^{77}$; Useful criteria:Technological attributes: the efficiency of processing an operation, the number of different operations a machine can perform, the fraction of an operation that can be transferred during disturbances, the probability of transferring an operation to alternate routes.

Modeling approach: Mathematical model measures the capacity to capture a number of different attributes common to many manufacturing systems.

12. Good support for hypotheses test in an apparel industry $^{28}$ :

Useful criteria:The governance mechanisms are used in the form of: supplier qualification programs and incentive structures based on hostages.

Modeling approach: This model is a mathematical approach which is carried out the firm strategy between the customer relationship (downstream) and supplier relationship (upstream). It is contingent on how a related relationship outside of the focal dyad is organized.

\section{Supply Contract}

It will explain contractual conditions ${ }^{9}$ :

i) Unit Price

ii) Minimum Order Quantity

iii) Order Quantity reduction penalty

Supply price per unit $(\mathrm{P})$ : This is the FOB (Freight on Board) unit price at which the supplier will deliver the component to the buyer for the contract life. No quantity discount is applied to this price. Penalties will be imposed on this price when the buyer places orders outside the limits specified in the supply contract.Minimum order quantity $\left(\mathrm{Q}_{\min }\right)$ : The buyer commits with the supplier to a minimum order quantity i.e. the buyer is made long term commitment with the supplier. When orders are below the minimum quantity then a price penalty is imposed. The buyer also has option not to order when demand is dropped and there is no penalty for this. Order quantity reduction penalty $(\beta)$ : This is the maximum penalty paid by the buyer when the order quantity is below $\mathrm{Q}_{\min }$. The penalty is linearly graded as a function of the order quantity i.e. if the order quantity is $\mathrm{Q}$ in any period, the quantity penalty is $\beta\left(\mathrm{Q}_{\min }-\mathrm{Q}\right) / \mathrm{Q}_{\min }$ when $\mathrm{Q}_{\text {lost }}<\mathrm{Q}<\mathrm{Q}_{\min }$. Here, $\mathrm{Q}_{\text {lost }}$ is the demand level below which management decides to loss the current sales rather than pay the order quantity penalty. The penalty $\beta$ protects both the buyer and supplier, and must therefore be carefully negotiated. The above mentioned three parameters are determined as part of the supplier-buyer negotiations and supply flexibility in the relationship. When multiple suppliers are available, the buyer must select the one which provides the best flexibility and least expected supply cost ${ }^{9}$.

\section{TYPES OF FLEXIBILITIES}

FLEXIBILITIES RELATED TO THE MODELING Delivery flexibility: It is the ability to change plant delivery dates ${ }^{23}$. Mass customization and outsourcing are forcing companies to get reasonable ways to meet customer demand ${ }^{24}$. It is a measure of calculating supply chain flexibility by varying supply quantities and lead times ${ }^{25}$. Marketing is usually in charge of distribution or delivery flexibility and it tries to establish widespread access of products ${ }^{26}$. It is the ability of a system to reduce the $\operatorname{order}^{27}$. Delivery uncertainty $^{28}$ is the level of uncertainty defined the specific date on which the component will be needed and/ or received (June 15, 2011 and/or December 22, 2011).Hence delivery flexibility leads to adjust the lead time for target product distribution; it is related with plant schedules and transportation system as presented in Table 1. It is the time-list of performer a particular supply chain activity such as production, storage, transportation, the management of information. At the strategic level, sourcing decisions determine what functions a firm performs and what functions the firm outsources. These decisions affect both the responsiveness and efficiency of a supply chain: a) Supply lead time-the average time between when an order is placed and the item arrives; b) Days payable outstanding-the number of days between when a supplier performed a supply chain task and when it is paid; c) Fraction of on time deliveries- the fraction of deliveries from the supplies that were on time; d) Supplier reliability- the variability of the supplier's lead time as well as the delivered quantity relative to plan; e) Processing or idle time- the fraction of time that the facility was processing units, being set up to process units; f) Flow time efficiency- the ratio of the theoretical flow time to the actual average flow time. Low values for flow time efficiency indicate that a large fraction of time is spent waiting.

It is the moving inventory from point to point in the supply chain. Transportation choices have a large impact on supply chain responsiveness and efficiency. It can take the form of many combinations of modes and routes, each with its own performance characteristics. a) Order Size- the average number of units or dollars in each incoming order of a facility; b) Average Inbound Transportation Cost- the cost of bringing item into a facility in a percentage of sales or cost of goods sold (COGS). Ideally, the cost should be 
measured per unit brought in, but this can be difficult. The inbound transportation cost is generally included in COGS. It is useful to separate this cost by supplier; c) Average inbound transportation cost per order- the average transportation cost of each incoming delivery. Along with the incoming order size, this flexibility identifies opportunities for greater economies of scale in inbound transportation; d) Fraction transported by mode- the fraction of transportation (in units or dollars) using each mode of transportation. This metric can be used to estimate if certain orders are overused or underutilized. Transportation is familiar on routing, transit time, freight, insurance, packaging, stowage areas, together with any constraints. Measurement influences the product specification such as whether of the goods are shipped as componentized break bulk or as a complete unit. The supply chain manager tries to focus on improving the utilization of the cubic capacity of the container. The benefits and compatibility of the system throughout supply chain should be evaluated continuously.

Delivery flexibility $=f$ (lead time, transportation $)$

Logistics flexibility: It is described that the ability to cost effectively receive and deliver product as sources of supply and customers change (customer location changes, globalization and postponement $)^{29}$.

We can analyze that logistic flexibility includes changes of customer and market, globalization, performance duration as presented in Table 2. It is a cost effective reconfigure receiving and delivering products. These are the physical locations where items are stored, assembled and fabricated. The two major sites: production and storage. The logistics functions are related to corporate on movement and storage activities that must be performed by any company regardless of strategic determination, has increasingly been targeted for outsourcing. Decisions regarding the role, location, capacity and flexibility of facilities have a significant impact on the supply chain's performance. New customer service requirements, competitive offerings and services, ordering methods influence logistics practices. Now we can summarize that the mechanism of distributing goods in a cost effective and efficient manner and the related organization, resource and technology to perform this objective, which can be concluded as the ability to get the right product at the right price and the right time.

Logistics flexibility $=f($ location, transportation time $)$
Market flexibility: It is carried out the ability to mass customize and build close relationships with customers, including designing and modifying new and existing products. Actually in competitive and uncertain market flexibility, firms can gain advantage from decreasing fixed assets ${ }^{30}$. It is a demand driven flexibility involve knowledge of other departments in the total supply chain. Demand flexibility explains the responsiveness to changing customer needs and wants and it is the ability to react quickly to unpredictable demand ${ }^{29}$.

Market is the biggest-potential flexibility of performance in the supply chain because it directly affects each of the other flexibilities. It presents management with the opportunity to make supply chains more responsive and more effective. It reduces variation in supply chain element. It consists of data and analysis concerning facilities, inventory, transportation, costs, prices and customers throughout the supply chain.

a) Forecast horizon- determines how far in advance of the actual event a forecast is made. The forecast horizon must equal the lead time of the decision that is driven by the forecast, b) Forecast error- the difference between the forecast and the actual demand. The forecast error is a measure of uncertainty and drives all responses to uncertainty such as safety inventory or excess capacity, c) Variance from plan - the differences between the planned item or inventories and the actual values. These variances can be used to raise flags that identify shortages and surpluses. Information system has good impact on variance of demand and plan. d) Ratio of demand variability to order variability- the standard deviation of incoming demand and supply orders placed as presented in Table 3 . It should consider 'Bullwhip effect' from seasonal data. Three basic aspects of any supply chain flexibility depend on an information system capable of providing current demand information, capable of delivering required materials with short lead time. Back order means the number of items had backordered due to stock out ${ }^{3}$. Average backorder level is the ratio of items backordered to the total number of items. Stock out probability is a fraction of requested item that is out of stock. We can say that market flexibility is the ability to mass customize by designing and modifying new and existing products. It builds close relationships with customers but it has uncertainties in every step.

$$
\begin{gathered}
\text { Market flexibility }= \\
f(\text { market volume, market uncertainties) }
\end{gathered}
$$

Mix flexibility: It is the ability to change the variety of products produced ${ }^{3}$. It includes broad product line and caters to different market segments and it defines of a 
system to produce a number of different products in a specific period simultaneously ${ }^{31}$. Product mix flexibility is a combination of machine flexibility, routing flexibility, control flexibility and tool flexibility. Mix uncertainty is the level of uncertainty equal to the exact $\mathrm{mix} /$ specification of a component ('green' or 'yellow').

We can say that it includes stationary product as multiple demand and return. Innovative product combines high fashion and first technological development ${ }^{19}$. Products with short life-cycles are increasingly major sources of profits for manufacturing companies. Products receive a greater challenge in matching supply and demand for manufacturer compared to functional counterparts as shown in Table 4. The inherent uncertainty in the demand for products, manufacturers must create accurate response techniques of producing and delivering product in the correct quantities at the correct time. Staple items generate greater profits in mature and price driven market with longer life cycles and less demand variability in a firm's product line. Today's customers do not accept standardized products as they have in the past. Product is a source of intense competition with a cause of uncertainty . With diverging customer needs, it becomes highly difficult for the supply chain to accommodate the customer needs into a product design and to predict the level of demand for a certain product with its life cycle concepts. The introduction of new products involve some time for development and set up $\operatorname{cost}^{3}$. Product standardization are driven by market development, cost-benefit relationship, legal requirements, competition, product support system, product life cycle, physical environment, market conditions, buying power, media, culture, green environmental issues, economic zones and customs. Decisions are made on speculation. Customer service standards are defined by the competitive environment and are customer driven. In the supply chain, the resources are directed to those specific products and customers that provide the company with a competitive advantage. Outsourcing, off shoring or contracting create transfer uncertainty in a supply chain elements. Demand uncertainties vary with the nature of the product, with functional products being less risky than innovative products ${ }^{20}$.

$$
\text { Mix flexibility }=f \text { (type of products, demand) }
$$

Operational flexibility: This kind of flexibilities which can be described (both manufacturing and service) by ability to configure assets and operations to react to emerging customer trends (product changes, volume, mix) at each node of the supply chain ${ }^{30}$. Operational measures are developed: i) operational costs: This aggregates the cost-volume of transactions in handling customer requests per day that include number of orders processed per day, electronic transmissions per day and shipments per day; ii) utilization: Percentage utilization is determined by the actual utilization of the system, equipment and facility space over the highest capacity of each of the categories ${ }^{25}$ and iii) set-up-time. Other issues of the operations systems dimensions include: It is the flexibility which is associated with the design of manufacturing systems ${ }^{24}$. It is the ability to transfer production from one site to another, ability to successfully respond when capacity is constrained and change production volumes, batch sizing. It is the ability of a firm to react quickly to a change in the environment by modifying the operation and a firm can mitigate the impact on the operation by taking proactive decisions $^{29}$.

From above concepts, we can conclude that operational flexibility is a design of product batch manufacturing system which classifies cost, set up time and utilization as presented in Table 5. Other related configures are mix, volume, equipment, facility with dynamic capacity and environment or ergonomics etc. It includes product changes, rapid process change in volume, product mix. It is the ability to assign assets and operations to react to emerging customer trends at each node. Operational flexibility refers to the planning, control, execution and improvement of the processes that transform inputs into products and services that the company provides to its internal and external customers. They create value by transforming: a) product form (as in manufacturing and education), b) location (as in transportation), c) time availability (as in inventory storage), d) exchange (as in retailing) e) physiological (as in health care) and f) information (as in telecommunication).

$$
\begin{gathered}
\text { Operational flexibility }= \\
f \text { (quality, operation time, operation cost) }
\end{gathered}
$$

Organizational flexibility: It is recognized that the team organization of the labor force can promote enterprise productivity as well as workers' skill levels have a great effect on enterprise economic efficiency. Labor flexibility is the basic flexibility to change the number of workers, tasks performed and their responsibilities. It is described that the ability to align labor force skills to the needs of the supply chain to meet customer service and demand requirements ${ }^{29}$. Other issues of organizational flexibility dimensions may include: cross functional integration and employee participation. It includes workplace flexibility and flexible knowledge workers ${ }^{24}$. Organizational preparedness has four dimensions: flexibility, awareness, empowerment, communication and organizational sustainability are the combinations of goals and objectives. 
Hence organizational flexibility refers to the extent to which coordinating organizations possess cultures, business objectives, managerial philosophies, and styles that are similar to, or complement, each other. It is the level of comfort that can support coordination of flows. On the other hand, the conflicting organizational artifacts may lead to a lack of trust and negative attitudes towards other coordinating flexibilities ${ }^{32}$. Workforce performance management involves with the following: applying industrial engineering principles to create an environment for productive workforce, adopt a plan on the basis of demand and technology to allocate human resources, provide sign in and sign out track time and attendance information, maintain a standard real time performance measurement technology, provide rewards, incentives or discipline based on every day performance as shown in Table 6 . Language, ethics, religion, economic and political systems, rules and regulations, protocols and immigrations are the cultural issues for driving a fastchanging market in many countries and regions of the world ${ }^{1}$. We can conclude that organizational flexibility is the ability to align labor force skills and capabilities to the needs of the supply chain to meet customer demand. It includes human resource management, organizational chart and workforce capability, personnel linkages in multicultural practices.

$$
\begin{array}{r}
\text { Organizational flexibility }= \\
f \text { (cost/ salaries, workforce nos.) }
\end{array}
$$

Product flexibility: It is the ability to introduce and produce new products (this includes the modification i.e. nos. of size or design of existing products) ${ }^{3}$. New product flexibility is the ability of a system for technology intensive markets to add or substitute new products to the product mix in a short time $\operatorname{span}^{29}$. It is the ability of a plant to perform new products or derivatives of new concept respect to existing one ${ }^{25}$. Product development is the ability to design various products in a short time $\operatorname{span}^{30}$. We can say that it is the ability to launch revised and/ or new products with cost and time management as presented in Table 7. Strategic partnership of the businesses change the way information is shared and inventory is managed within a supply chain. On the other hand, transferring point-ofscale (POS) data from the manufacturer to its supplier can help reduce lead times significantly because the supplier can anticipate an incoming order by studying POS data. This study is carried out that markets are actively searching for suppliers with shorter lead times and many potential customers consider lead time a very important criterion for decision making. Effective information systems cut lead times by considering lead time factors i.e. order processing, paperwork, stock picking, transportation delays and so ${ }^{24}$. If the supply order rapidly propagates up the supply chain through the tiers of retailers as far back as is necessary to meet the order, lead time can be greatly reduced. Increasing lead time affects the inventory level of the storing capacity of a growing business. It fixes how much a firm will charge for goods and services that it makes available in the supply chain. It affects the behavior of the buyer of the good or service, thus acting supply chain performances: a) Profit margin determines the profit as a percentage of revenue. A store needs to examine a wide variety of profit margin flexibility to optimize its pricing, including dimensions such as type of margin (gross, net etc), scope (market share, division, item), customer type and others; b) Days sales outstanding- the average product selling time between when a sale is made and when the cash is collected; c) Incremental fixed cost per order-the incremental costs that are independent of the size of the order. These include changeover costs at item delivery place or order processing or transportation costs that are incurred independent of order size at a mail order firm; d) Incremental variable cost per unit- the incremental cost that vary with the size of the order. These include picking costs at a mail-order firm or variable item cost at delivery places; e) Range of periodic sales- the maximum and minimum of the quantity sold per period (day, week and month) during a specified time horizon. The goal is to understand any correlation between sales and price and any potential opportunity to shift sales by changing price over time.

$$
\begin{gathered}
\text { Product flexibility }= \\
f \text { (product launch time, product cost) }
\end{gathered}
$$

Volume flexibility: It is the ability to change the output level of products produced ${ }^{3}$. For a volatile market, it defines a system to change the production level and the composition of the product mix significantly in a short time $\operatorname{span}^{31}$. Manufacturing and production flexibility is the ability to handle mix and volume flexibility in postponement and low switching costs. Volume uncertainty is related to the actual volume demanded of a specific component and/ or the real volume (20 or 30 units) of a component will be received ${ }^{29}$.Volume flexibilities include: a) product capacity- the maximum amount a facility can process; b) utilization- the fraction of capacity that is currently being used in the facility; c) production cost per unit-the average cost to produce a unit of output. These costs can be measured per unit item, per case, per pound depending on the item; d) theoretical flow/cycle time of production-the time required to process a unit if there are absolutely no delays at any range; e) actual average flow/ cycle timemeasures the average actual time taken for all units processed over a specified duration such as a week or month. The flexibility should be measured when setting 
due dates for orders. f) product variety- the number of products/product families processed in a facility. Processing costs and flow times are likely to increase with product variety. g) volume contribution of top 20 percent customers- the fraction of total volume processed by a facility that comes from the top 20 percent customers. An 80/20 outcome in which the top 20 percent contribute 80 percent of volume indicates likely benefits from focusing the facility where separate processes are used to process the top 20 percent and the remaining 80 percent. We can conclude that it is the quick and efficient adjustment of output to match demand. Usually manufacturing is related to volume flexibility Table 8. A manufacturing plant that can operate at the same production costs, quality levels and its profitability in maximum and minimum margin is the measurement of flexibility as shown in Table 8 . Product volume can be defined 'market flexibility' but it does not contain any uncertainty.

Volume Flexibility $=f($ products volume $)$

(viii)

\section{Measurement parameters for flexibilities to obtain strategic goals}

\section{Delivery Flexibilities:}

Strategic goals: GEC Fashion will manufacture T-shirt and consistently deliver T-shirts to the customer on time at a reasonable cost.

Measurement parameters: Cost e.g. T-shirt lateness

\section{Logistics Flexibilities:}

Strategic goals: New strategies will be implemented that support corporate strategies and are based on the needs of the market place and distinct capabilities of the B.K. Engineering Ltd.

Measurement parameters: Transportation cost, e.g. Convenient (distance) market place.

\section{Market Flexibilities:}

Strategic goals:Beximco Textile will produce in uncertain high quality and various lot sizes product which will confirm customer demand.

Measurement parameters: Product demand with different flexibilities: quality and profit

4. Mix Flexibilities:

Strategic goals: Honda Ltd. will provide high quality custom-designed product at the optimum possible cost.
Measurement parameters: Product quality

5. Operational Flexibilities:

Strategic goals: Motorola Ltd. is planning to build-toorder production and postponement production systems in markets with quickly obsolete existing products considering customer requirements and evaluating product life cycles.

Measurement parameters: System cost, production time and equipment utilization.

6. Organizational Flexibilities:

Strategic goals: Hotel Sheraton manager is trying to understand the potential benefits, employee empowerment as well as the costs of developing a new unit so that appropriate business decisions can be made.

Measurement parameters: Number of new employees with catering services and salary scales.

\section{Product Launch Flexibilities:}

Strategic goals: Wind mobile has highly innovative products with constantly changing environments system that speed up the market by focusing on strategic performances.

Measurement parameters: Product launch time and product price.

\section{Volume Flexibilities:}

Strategic goals: Coca Cola produces 3 millions of products per month by its three units in two shifts. If it allows night (third) shift for three units, its products will increase $20 \%$ but market has excess demand only $15 \%$.

Measurement parameters: Maximum and minimum volume should be allocated.Finally, we can sum up :

Supply Chain Flexibility

$=f$ (delivery flexibility, logistics flexibility,

market flexibility, mix flexibility, operational

operational flexibility, organizational

flexibility, product flexibility, volume flexibility). 


\section{Measurement of supply chain flexibilities}

Table 1: Delivery flexibility with applications

\begin{tabular}{|c|c|}
\hline $\begin{array}{l}\text { Name of } \\
\text { flexibility }\end{array}$ & Delivery flexibility \\
\hline Definition & $\begin{array}{l}\text { It is the ability to adjust lead time } \\
\text { and transportation system. }\end{array}$ \\
\hline $\begin{array}{l}\text { System } \\
\text { applications }\end{array}$ & $\begin{array}{l}\text { Delivery dates change frequently } \\
\text { and transportation modes with } \\
\text { lead time improve system } \\
\text { performance. }\end{array}$ \\
\hline $\begin{array}{l}\text { Functional } \\
\text { Equation }\end{array}$ & $\begin{array}{l}\text { Delivery flexibility }=f(\text { lead time, } \\
\text { transportation cost }) \text {. }\end{array}$ \\
\hline $\begin{array}{l}\text { Measurement } \\
\text { of related } \\
\text { factors }\end{array}$ & $\begin{array}{l}\text { Lead time }= \\
\left\{\frac{\min \left\{t_{a}\right\}}{t_{a}}\right\} \text {,Transportation cost }= \\
\left\{\frac{\min \left\{c_{a}\right\}}{c_{a}}\right\} \\
\text { where, } a \in i, j, k\end{array}$ \\
\hline
\end{tabular}

Table 2: Logistics flexibility with applications

\begin{tabular}{|c|c|}
\hline $\begin{array}{l}\text { Name of } \\
\text { flexibility }\end{array}$ & Logistics flexibility \\
\hline Definition & $\begin{array}{l}\text { It is the ability to adjust time } \\
\text { and location. }\end{array}$ \\
\hline $\begin{array}{l}\text { System } \\
\text { applications }\end{array}$ & $\begin{array}{l}\text { System has the ability to } \\
\text { perform the right product at } \\
\text { the right price and the right } \\
\text { time. }\end{array}$ \\
\hline $\begin{array}{l}\text { Functional } \\
\text { Equation }\end{array}$ & $\begin{array}{l}\text { Logistics flexibility }= \\
f(\text { location, transportation } \\
\text { time). }\end{array}$ \\
\hline $\begin{array}{l}\text { Measurement of } \\
\text { related factors }\end{array}$ & $\begin{array}{l}\text { Delivery/ } \\
\text { receivingtime }= \\
\left\{\frac{\min \left\{t_{a}\right\}}{t_{a}}\right\}, \text { Distance }= \\
\left\{\frac{\min \left\{d_{a}\right\}}{d_{a}}\right\}, \text { Logisticcost }= \\
\left\{\frac{\min \left\{c_{a}\right\}}{c_{a}}\right\}, \text { where, } a \in i, j, k .\end{array}$ \\
\hline
\end{tabular}

Table 3: Market flexibility with applications

\begin{tabular}{ll}
\hline \hline Name of flexibility & Market flexibility \\
\hline \hline Definition & It is the ability to \\
& customize products by \\
& designing and modifying \\
& new and existing hose \\
& products. \\
\hline
\end{tabular}

\begin{tabular}{ll}
\hline System applications & $\begin{array}{l}\text { It sets close relationships } \\
\text { with customers but it has } \\
\text { uncertainties in every step. }\end{array}$ \\
\hline Functional equation & $\begin{array}{l}\text { Market flexibility= } \\
f \text { (market volume/ demand, } \\
\text { market uncertainties). }\end{array}$ \\
\hline Measurement of & $D \sim N(\mu, \sigma) ; D=f(x)$, \\
related factors & $F(x)=\int_{o}^{X} d x . \quad 0 \leq F(x) \leq 1$, \\
& $D=\mu+\sigma z$. \\
& $\mu$ and $\sigma$ represent the mean \\
& and standard deviation of \\
demand during the \\
replenishment lead time \\
and z is the percentile ratio \\
of standard normal \\
distribution.
\end{tabular}

Table 4: Mix flexibility with applications

\begin{tabular}{ll}
\hline \hline $\begin{array}{l}\text { Name of } \\
\text { flexibility }\end{array}$ & Mix flexibility \\
\hline \hline Definition & $\begin{array}{l}\text { It is the ability to meet the } \\
\text { demand with various types of } \\
\text { products. }\end{array}$ \\
\hline $\begin{array}{l}\text { System } \\
\text { applications }\end{array}$ & $\begin{array}{l}\text { It is related to product } \\
\text { diversification with demand. }\end{array}$ \\
\hline $\begin{array}{l}\text { Functional } \\
\text { equation }\end{array}$ & $\begin{array}{l}\text { Mix flexibility=f(types of } \\
\text { product). }\end{array}$ \\
\hline $\begin{array}{l}\text { Measurement of } \\
\text { related factors }\end{array}$ & $\begin{array}{l}\text { Types of product, } M_{i j} \\
=\frac{\left|\Omega_{i} \cap \Omega_{j}\right|}{\left|\Omega_{i} \cup \Omega_{j}\right|}\end{array}$ \\
& and $M_{j k}=\frac{\left|\Omega_{\Omega_{j} \cap \Omega_{k}}\right|}{\left|\Omega_{j} \cup \Omega_{k}\right|}$ \\
\hline
\end{tabular}

Table 5: Operational flexibility with applications

\begin{tabular}{ll}
\hline \hline Name of flexibility & Operational flexibility \\
\hline \hline Definition & $\begin{array}{l}\text { It is the ability to design a } \\
\text { product batch } \\
\text { manufacturing system } \\
\text { which classifies volume, } \\
\text { utilization, reconfigure } \\
\text { equipment, facility with } \\
\text { dynamic capacity and } \\
\text { environment. }\end{array}$ \\
\hline System applications & $\begin{array}{l}\text { It is related to set up cost } \\
\text { and set up time. }\end{array}$ \\
\hline Functional equation & $\begin{array}{l}\text { Operational flexibility= } \\
f(\text { set up cost, set up time, } \\
\text { utilization). }\end{array}$ \\
\hline Measurement of & Set up time $=\left\{\frac{\min \left\{t_{a}\right\}}{t_{a}}\right\}$, \\
\hline
\end{tabular}




\begin{tabular}{ll}
\hline related factors & Utilization $=\left\{\frac{u_{a}}{\max \left\{u_{a}\right\}}\right.$, \\
& Set up cost $=\left\{\frac{\min \left\{c_{a}\right\}}{c_{a}}\right\}$, \\
& where, $a \in i, j, k$
\end{tabular}

Table 6: Organizational flexibility with applications

\begin{tabular}{|c|c|}
\hline Name of flexibility & Organizational flexibility \\
\hline Definition & $\begin{array}{l}\text { It is the ability to align labor } \\
\text { force skills and capabilities } \\
\text { to the needs of the supply } \\
\text { chain to meet customer } \\
\text { demand. }\end{array}$ \\
\hline $\begin{array}{l}\text { System } \\
\text { applications }\end{array}$ & $\begin{array}{l}\text { It includes human resource } \\
\text { management, organizational } \\
\text { chart and workforce } \\
\text { capability, personnel } \\
\text { linkages in multicultural } \\
\text { practices. }\end{array}$ \\
\hline $\begin{array}{l}\text { Functional } \\
\text { equation }\end{array}$ & $\begin{array}{l}\text { Organizational flexibility }= \\
f(\text { cost, work force nos. }) .\end{array}$ \\
\hline $\begin{array}{l}\text { Measurement of } \\
\text { related factors }\end{array}$ & $\begin{array}{l}\text { Work force }= \\
\left\{\frac{\min \left\{w_{a}\right\}}{w_{a}}\right\}, \text { Salary }= \\
\left\{\frac{\min \left\{s_{a}\right\}}{s}\right\}, \text { where, } a \in i, j, k\end{array}$ \\
\hline
\end{tabular}

Table 7: Product flexibility with applications

\begin{tabular}{ll}
\hline \hline $\begin{array}{l}\text { Name of } \\
\text { flexibility }\end{array}$ & Product flexibility \\
\hline \hline Definition & $\begin{array}{l}\text { It is the ability to launch revised } \\
\text { and/ or new products with cost } \\
\text { and time management. }\end{array}$ \\
\hline $\begin{array}{l}\text { System } \\
\text { applications }\end{array}$ & $\begin{array}{l}\text { New products indicate } \\
\text { modifying system with } \\
\text { diversified concepts. }\end{array}$ \\
\hline $\begin{array}{l}\text { Functional } \\
\text { equation }\end{array}$ & $\begin{array}{l}\text { Product flexibility=f(cost, } \\
\text { product launch time). }\end{array}$ \\
\hline $\begin{array}{l}\text { Measurement } \\
\text { of related } \\
\text { factors }\end{array}$ & $\begin{array}{l}\text { Time to launch a product }= \\
\left\{\frac{\min \left\{t_{a}\right\}}{t_{a}}\right\}, \text { Planning, } \\
\text { designing and product cost }= \\
\left\{\frac{\min \left\{c_{a}\right\}}{c_{a}}\right\}, \text { where, } a \in i, j, k .\end{array}$ \\
\hline
\end{tabular}

Table 8: Volume flexibility with applications

\begin{tabular}{ll}
\hline \hline $\begin{array}{l}\text { Name of } \\
\text { flexibility }\end{array}$ & Volume flexibility \\
\hline \hline Definition & $\begin{array}{l}\text { It is the ability to measure } \\
\text { product volume. }\end{array}$ \\
\hline $\begin{array}{l}\text { System } \\
\text { applications }\end{array}$ & $\begin{array}{l}\text { Volume flexibility can be } \\
\text { defined by 'market flexibility' } \\
\text { but it does not contain any } \\
\text { uncertainty. }\end{array}$ \\
\hline $\begin{array}{l}\text { Functional } \\
\text { equation }\end{array}$ & $\begin{array}{l}\text { Volume flexibility= } f \text { (products } \\
\text { volume) }\end{array}$ \\
\hline $\begin{array}{l}\text { Measurement of } \\
\text { related factors }\end{array}$ & $\begin{array}{l}\text { Volume flexibility, } V f= \\
\left\{\frac{V_{\max }-V_{\min }}{V_{\max }}\right\}, \text { Range of } V_{f}=0 \\
\text { to } 1 .\end{array}$ \\
\hline
\end{tabular}

\section{Mathematical modeling:How to measure with equations and binary variables}

If we consider $I=$ Total no. of Suppliers, $J=$ Total no. of Manufacturing systems and $K=$ Total no. of markets i.e., $i, j$, and $k$ are the individual representatives for each network. Now, we can consider binary variable for supplier to manufacturer,

$X_{i j}=\left\{\begin{array}{lr}1 & \text { if product } i \text { can be assigned to location } j \\ 0 & \text { otherwise }\end{array}(1)\right.$

Notations for eight types of flexibilities: Delivery flexibility $(d)$, Logistics $(l)$, Market $(m)$, Mix $(M)$, Operational (op), Organizational (or), Product (p), Volume $(v)$. It is important to examine the significance of the supply chain position [Figure A] and integrate the values of supplier, manufacturer and market in a supply network ${ }^{3}$.

Supplier to Manufacturer: We can consider suppliers with individual weight and assign them to the manufacturer that has their highest performance. This efficiency measurement process is to be accounted until every supplier has been estimated. Here $e_{d c i j}$ that defines in the model represent cost based efficiency, which indicates how well a supplier $i$ can process the order to the manufacturer $j$ with respect to delivery cost as $0 \leq e_{d c i j} \leq 1$.

$$
\text { Delivery cost-based efficiency, } \boldsymbol{e}_{\boldsymbol{d} \boldsymbol{i j}}=\frac{\boldsymbol{m i n}\left\{\boldsymbol{d} \boldsymbol{c}_{\boldsymbol{i j}}\right\}}{\boldsymbol{d} \boldsymbol{c}_{\boldsymbol{i j}}}
$$

For an individual process supplier to manufacturer, $e_{d t i j}$ is the ratio of the minimum time to process a supplier in the possible set of options with respect to time to process supplier i. We can get as follows, 
Delivery time-based efficiency, $\boldsymbol{e}_{\boldsymbol{d} t \boldsymbol{i j}}=\frac{\boldsymbol{m} \boldsymbol{m}\left\{\boldsymbol{d} \boldsymbol{d t}_{\boldsymbol{i j}}\right\}}{\boldsymbol{d} \boldsymbol{t}_{\boldsymbol{i}}}(3)$

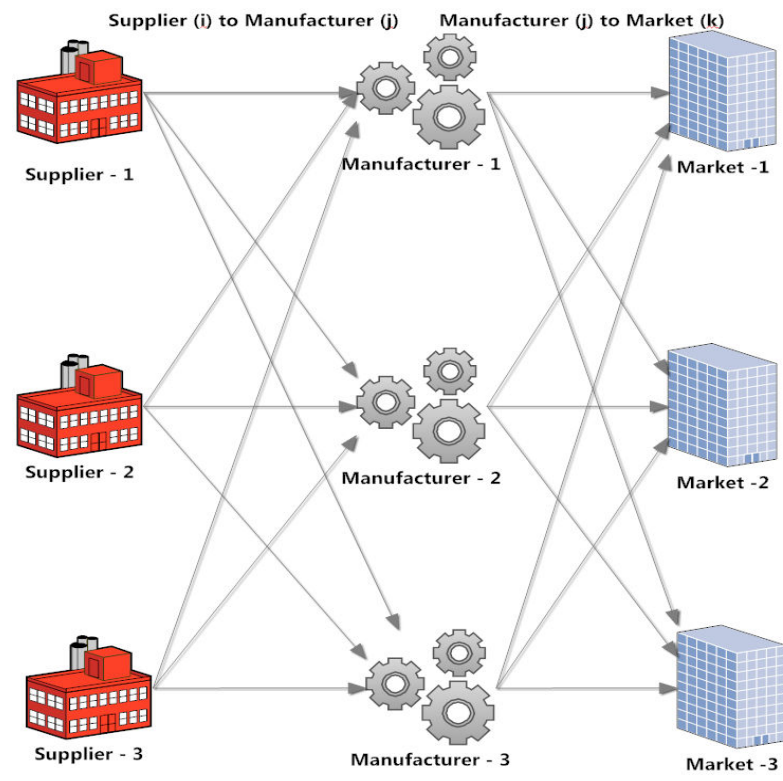

Figure A: Networking system for supplier $(i)$ to manufacturer $(j)$ and manufacturer $(j)$ to market $(k)$.

For this modeling we consider maximum value for utilization, demand volume and minimum value for delivery cost, lead time, distance, transportation cost, set up time, product launch time, work force, salaries and benefits, product cost, set up cost and optimum values for types of product.

There are four dimensions [32] to measure supply chain flexibility: i) no of tasks, products and options, ii) heterogeneity among tasks and products, iii) mobility of time, cost and effort, iv) identical performance of quality, cost and time.

$$
\begin{aligned}
& \text { Delivery flexibility efficiency, } \\
& e_{1 i j}=\left\{\frac{\min \left\{d t_{i j}\right\}}{d t_{i j}}\right\}\left\{\frac{\min \left\{d c_{i j}\right\}}{d c_{i j}}\right\} X_{i j}
\end{aligned}
$$

Similarly for logistic flexibility we can minimize logistic time, logistic distance and logistic cost to get efficiency.

$$
\begin{aligned}
& \text { Logistic flexibility efficiency, } e_{2 i j} \\
& =\left\{\frac{\min \left\{l t_{i j}\right\}}{l t_{i j}}\right\}\left\{\frac{\min \left\{l d_{i j}\right\}}{l d_{i j}}\right\}\left\{\frac{\min \left\{l c_{i j}\right\}}{l c_{i j}}\right\} X_{i j}
\end{aligned}
$$

Supply uncertainty is strongly affected by the life-cycle position of the item. New components being introduced have higher market uncertainty because consumption and production processes are still evolving. Usually, mature product has less uncertainty. It is pointed out that along with the demand uncertainty, it is important to consider uncertainty resulting from the capability of the business performance [19]. For market flexibility, percentile ratio of standard normal distribution is the function of mean, standard deviation and demand replenishment,

Percentile ratio of standard normal, $z_{i j}=\frac{d m_{i j}-\mu m_{i j}}{\sigma m_{i j}}$

Cumulative of percentile ratio (Function of $\mathrm{z}$ value) indicates individual efficiency for market flexibility,

$$
\text { Market flexibility efficiency, } e_{3 i j}=F\left(z_{i j}\right)
$$

Mix flexibility efficiency describes to meet the demand for individual product with respect to total diversification capacity products,

$$
\text { Mix flexibility efficiency, } e_{4 i j}=\left\{\frac{\mid \Omega_{i} \cap \Omega_{j}}{\mid \Omega_{i} \cup \Omega_{j}} \mid\right\} \cdot X_{i j}
$$

It is aptly said that when a supplier process a product to multi-level manufacturer; it may process the product with different efficiency as that of their available technology and existing facilities [17]. Similarly, a manufacturer can select multi-channel market as his/ her customers demand with different efficiency. This can be differentiate with factors of flexibilities cost, time, demand, volume and utilization etc. Usually maximum (highest) margin is expected for demand, utilization and volume. When the availability of technology is zero, the magnitudes for three factors should be minimum (zero) i.e. minimum value should be divided by maximum value for obtaining a reasonable solution. That means maximum deficiency is calculated as existing system does not work; but other cost are introduced for over all supply chain management. When technological availability for both of the chains are $100 \%$; then supply chain flexibility, SF is lowest magnitude.

Operational flexibility includes set up time, operational utilization and set up cost. We consider minimum efficiency for set up time and set up cost and maximum efficiency for utilization.

$$
\begin{aligned}
& \text { Operational flexibility efficiency, } e_{5 i j}= \\
& \left\{\frac{\min \left\{o t_{i j}\right\}}{o t_{i j}}\right\}\left\{\frac{o u_{i j}}{\max \left\{o u_{i j}\right\}}\right\}\left\{\frac{\min \left\{o c_{i j}\right\}}{o c_{i j}}\right\} X_{i j}
\end{aligned}
$$

Organizational flexibility is the function of work force and payment of salary. Usually every organization tries to minimize its work force but in an efficient way, so 
minimization of payment of salary should be considered to obtain strategic goal.

$$
\begin{aligned}
& \text { Organizational flexibility efficiency, } \boldsymbol{e}_{6 i j}= \\
& \left\{\frac{\boldsymbol{m i n}\left\{\boldsymbol{o w}_{i j}\right\}}{\boldsymbol{o} \boldsymbol{w}_{i j}}\right\}\left\{\frac{\boldsymbol{m i n}_{i j}\left\{\boldsymbol{s}_{i j}\right\}}{\boldsymbol{o} s_{i j}}\right\} X_{i j}
\end{aligned}
$$

Minimum product-launch time and minimum product cost are the targets for product flexibility efficiency.

$$
\begin{aligned}
& \text { Product flexibility efficiency, } \\
& e_{7 i j}=\left\{\frac{\min \left\{p t_{i j}\right\}}{p t_{i j}}\right\}\left\{\frac{\min \left\{p c_{i j}\right\}}{p c_{i j}}\right\} X_{i j}
\end{aligned}
$$

Maximum and minimum volume without uncertainty indicates volume efficiency. It should always lies between 0 and 1 .

$$
\begin{aligned}
& \text { Volume flexibility efficiency, } \\
& e_{8 i j}=\left\{\frac{v_{i j m a x}-v_{i j \min }}{v_{i j \max }}\right\} X_{i j}
\end{aligned}
$$

Now we can consider individual weight for each of flexibility as situation apply. Weight efficiency is more fluctuate for manufacturer to market than supplier to manufacturer. It indicates that volume is more stable for supplier to manufacturer but market demand is uncertain for manufacturer to market. Weight is the probable influences of assigning flexibility on supplier $i$ to manufacturer $j$ and manufacturer $j$ to market $k$. $0 \leq w_{i j} \leq 1$. The weighted efficiency of supplier ito manufacturer $j$ and manufacturer $j$ to market $k$ depend on the performance of individual flexibility [18]. A remarkable value for the demand probability of supplier influences a higher probability of assigning supplier, $i$ to manufacturer $j$. Similarly the higher the value weight for an individual flexibility from manufacturer $j$ to market $k$; the product can occupy more impact in the customer satisfaction.

Weight efficiency for supplier to manufacturer,

$$
e_{i j}=\sum_{f=1}^{8} w_{f_{i j}} e_{f_{i j}}
$$

Weight for each flexibility from supplier to manufacturer, $w_{i j} ; \sum_{f=1}^{8} w_{f_{i j}}=1, \quad \forall \in i, j$

\section{Manufacturer to market}

As technology absorption is the main component of all flexibilities; so competition between supply chain players should utilize more accurate information and better communication technologies to respond quickly to changing customer requirements ${ }^{26}$. Manufacturers and markets should provide up to date and capable products, as well as process technologies to produce the material needed. Let us consider manufacturer to market,
$Y_{j K}=\left\{\begin{array}{lr}1 \text { if product } j \text { can be assigned to location } k \\ 0 & \text { otherwise }\end{array}\right.$

Similarly for manufacturer (j) to market (k), we can get,

$$
\begin{gathered}
\text { Delivery flexibility } \\
\text { efficiency, } \boldsymbol{e}_{1 j k}=\left\{\frac{\boldsymbol{m i n}\left\{d t_{j k}\right\}}{d t_{j k}}\right\}\left\{\frac{\boldsymbol{m i n}\left\{d c_{j k}\right\}}{d c_{j k}}\right\} \boldsymbol{Y}_{j k}
\end{gathered}
$$

Similarly

$$
\begin{aligned}
& \text { Logistisflexibilityefficiency, } e_{2 j k}= \\
& \left\{\frac{\min \left\{l t_{j k}\right\}}{l t_{j k}}\right\}\left\{\frac{\min \left\{l d_{j k}\right\}}{l d_{j k}}\right\}\left\{\frac{\min \left\{l c_{j k}\right\}}{l c_{j k}}\right\} Y_{j k}
\end{aligned}
$$

Customer demand may consider that each of the customer need categories should be viewed differently, but in a very fundamental sense, each customer need can be translated into the metric of implied demand uncertainty. Demand uncertainty reflects the uncertainty of customer demand for an item. Implied demand uncertainty is imposed on the supply chain because of the customer needs it seeks to satisfy. As a business raises its level of service, it must be able to meet a higher and higher percentage of actual demand, forcing it to prepare for rare surges in demand. Ultimately, raising the service level increases the implied demand uncertainty even though the item's underlying demand uncertainty does not change. Both the item demand uncertainty and various customer needs that the business strategy tries to fill affect implied demand uncertainty. It is pointed out that implied demand uncertainty is often correlated with other characteristics of demand ${ }^{19}$ :

i) Components with uncertain demand are often less mature and have less direct competition.

ii) Forecasting has more accurate when demand has less uncertainty.

iii) Markdowns are high for products with high implied demand uncertainty.

iv) Increased implied demand uncertainty leads to increased difficulty in matching supply with demand. For a given item, this dynamic can lead to either an oversupply or a stock out situation. i.e. a product with low implied demand uncertainty- such as salt- has a very low margin, accurate demand forecasts, low stock out rates and virtually no markdowns.

$\begin{aligned} & \text { Percentile ratio of standard } \\ & \text { normal distribution, } Z\end{aligned}=\frac{d m_{j k}-\mu m_{j k}}{\sigma m_{j k}}$ 


$$
\text { Market flexibility, } e_{3 j k}=F\left(Z_{j k}\right)
$$

Product availability justifies inventory management and forecasting. When customers decide to place orders, they fully expect that the desired products will be in stock. Information system refers to customer's perceptions of the information provided by the supplier regarding products, their availability and procedures for placing and receiving orders.

$$
\begin{aligned}
& \text { Mix flexibility efficiency, } e_{4 j k}=\left\{\frac{\left|\Omega_{j} \cap \Omega_{k}\right|}{\Omega_{\Omega_{j}} \cup \Omega_{k} \mid}\right\} Y_{j k} \\
& \text { Operational flexibility efficiency, } e_{5 j k}= \\
& \left\{\frac{\min \left\{o t_{j k}\right\}}{o t_{j k}}\right\}\left\{\frac{o u_{j k}}{\max \left\{o u_{j k}\right\}}\right\}\left\{\frac{\min \left\{o c_{j k}\right\}}{o c_{j k}}\right\} Y_{j k}
\end{aligned}
$$

$$
\begin{aligned}
& \text { Organizational flexibility efficiency, } e_{6 j k}= \\
& \left\{\frac{\min \left\{o w_{j k}\right\}}{o w_{j k}}\right\}\left\{\frac{\min \left\{o s_{j k}\right\}}{o s_{j k}}\right\} Y_{j k}
\end{aligned}
$$

Product quality defines to how well products work as compared as expectations. Product order timeliness means the customer's perceptions that orders arrived when they were expected to arrive. Manufacturers develop suppliers as well as market strengths and technology in support of new product and development [53].

$$
\begin{array}{r}
\text { Product flexibility efficiency, } e_{7 j k}= \\
\left\{\frac{\min \left\{p t_{j k}\right\}_{j k}}{p t_{j k}}\right\}\left\{\frac{\min \left\{p c_{j k}\right\}}{p c_{j k}}\right\} Y_{j k}
\end{array}
$$

Volume flexibiliy efficiency, $e_{8 j k}=\left\{\frac{v_{j k \max }-v_{j k \min }}{v_{j k \max }}\right\} Y_{j k}$

Weight efficiency for manufacturer to market, $e_{j k}=$

$$
\sum_{f=1}^{8} w_{f_{j k}} e_{f_{j k}} \forall \in j, k
$$

Weight for each of flexibility from manufacturer to

$$
\operatorname{market;} \sum_{f=1}^{8} w_{f_{j k}}=1
$$

Relationship among supply chain players, suppliermanufacturer-market: The priority for selecting a manufacturer for a supplier depends on lead time with combined efficiency. The combined efficiency is directly proportional to system performance for supplier to manufacturer and manufacturer to market. This leads to the probability of the assigning flexibilities to bring market capability for a product,

$$
\text { Combined Efficiency, } \mu_{i j k}=e_{i k} \times e_{j k} \forall \in i, j, k
$$

Demand uncertainty has no more impact as it is similar for all flexibilities. On the other hand, routing efficiency has similar change for combined efficiency. Combined efficiency has better impact compare to flexibilities weight, uncertainties of flexibilities and routing efficiency. The routing efficiency describes assigning different suppliers to alternate manufacturers and different manufacturers to alternate markets. On the other hand, network flexibility defines the possibility of reassigning different supplier, manufacturer and market among them. Combined and networking are effective for external and internal uncertainties respectively. Entrepreneurs who are concerns about customers should make priority to the external uncertainties as it consists of modifications made to account for customers demand, supply uncertainties and market growth ${ }^{19}$.

Networkinguncertainty, $\gamma_{i j k}=p_{i j} \times p_{j k} \forall \in i, j, k$ (26)

i.e., Probability for each flexibility with

networking, $P_{i j}$ and $P_{j k}$

$$
\sum_{1}^{3} P_{i j}=1 \quad \text { and } \quad \sum_{1}^{3} P_{j k}=1 \quad \forall \in i, j, k
$$

Combined flexibility can be measured in terms cost, range and time dimensions. The combined efficiency of operation $i, j, k$ can be computed as the product of efficiency $i, j, k$ performing a given operation divided by sum of the efficiency of total no of operations.

Network efficiency with link probability, $\varphi_{i j k}=$

$$
\gamma_{i J k} \times \mu_{i j k}
$$

Probability of risk is an exposure to negative consequences of uncertain events. The logical protections against risk are routine variability of inventory, capacity, time buffers etc. Hurricanes, political disruptions, acts of terrorism, currency crisis, technological breakthroughs and many other unpredictable events with natural hazards can have important influence on supply chain flexibilities. Order discrepancy handling explains that often orders are not accurate, in good condition, optimum price, of high quality or timely etc. The systems used by supply chain flexibility to address these discrepancies affect satisfaction level and influence order uncertainty. Order procedures indicate to the effectiveness and ease of placing orders. Order accuracy refers to the customer's perceptions of how closely shipments match the orders placed. Order condition reflects to the lack of damage to delivered goods ${ }^{26}$.

Networkingflexibilitywithlinkprobability, $e_{i j k}=$ $\frac{\varphi_{i j k}}{\Sigma \Sigma \sum \varphi_{i j k}}$ 
Total Supply Chain Flexibility, $S F=\frac{\sum \sum \sum e_{i j k} \log _{10} e_{i j k}}{\log (I J K)}$

Maximization of supply chain flexibility:

$$
\begin{aligned}
& \text { For equal probabilities, } e_{i j}=1 \text { ande }_{j k}=1 \\
& P_{i j}=\frac{1}{J} \text { and } P_{j K}=\frac{1}{K} \\
& \text { Combined Efficiency, } \mu_{i j k}=1
\end{aligned}
$$$$
\text { Networkinguncertainty, } \gamma_{i j k}=\frac{1}{J K} \text { and }
$$

Network efficiency and link probability, $\varphi_{i j k}=\frac{1}{J K}$

$$
\sum_{i} \sum_{j} \sum_{k} \varphi_{i j k}=\frac{1}{J K} . I J K=I
$$

Net work flexibility with link probability, $e_{i j k}=$

$$
\frac{1}{I K}=\frac{1}{I J K}
$$

Maximum Supply Chain Flexibility, $S F_{\text {max }}=$

$$
-\frac{1}{I J K} \sum \sum \sum \log \left(\frac{1}{I J K}\right)=\log (I J K)
$$

It is important to note that the values of the SF are useful that determine to make sense and to compare with one another. Actually, an extreme flexibility magnitude that is 0 or 1 indicate minimum and maximum flexibility limit and non-extreme values may not have so clear ideas with respect to marginal flexibilities. If a flexibility measure is 0.99 , then we can easily say that this system is flexible. If this value tends to 0.139 to 0.147 , it is difficult to say that the system as flexible; but we can estimate that the system is more flexible than another system whose flexibility value is $0.135^{25}$. Therefore, flexibility measure is a comparison between operations.

\section{Flexibility in proposed model}

This model explains the ability of a manufacturing system to adapt to various uncertainties. It considers a number of technological attributes, i.e. the efficiency of processing an operation, the number of different flexibilities with individual weights, and the probability of choosing a chain to alternate routes presented in this model. The role of flexibility has found the right balance between responsiveness and efficiency. Each flexibility affects business strategy. Having more flexibility generally makes a chain more responsive, while having fewer, central flexibilities creates higher efficiency. Holding higher levels of inventory increases the responsiveness of a chain, while keeping inventory low increases the chain's efficiency. Using faster modes of transportation increases a chain's responsiveness, while using slower modes generally increases efficiency. Expediting in information can vastly improve the supply chain performance on both dimensions.

\section{Graphical presentations of findings}

Strategic fit with supply chain flexibility is the history of the successful company and it means that both the competitive and business strategies i.e. individual weight of each flexibility, and players performances, have aligned goals as presented in Figure 1 . Appropriate sourcing decisions raise business profits by assigning supply chain functions at the right time to the right party, who brings higher economies of scale or a higher level of aggregation of uncertainty. Pricing can be used to attract the target customer segment. Differential pricing can be used to attract customers who value responsiveness as well as customers who want efficiency. The business strategy and supply chain flexibility can then be designed to provide responsiveness to potential customers while improving overall efficiency. Use of resources, the expected output, flexibility of the system and inter-relationship among factors play a major role to measure performances of a supply chain ${ }^{15}$.

\section{Sensitivity analysis}

The performance parameter and final supply chain configuration were determined, resulting in one supplier three manufacturers and nine markets. A 3 by 3 by 3 matrices was created. Maximum and minimum volume has a significant impact on flexibility. The total flexibility was evaluated while the maximum and minimum volume were changed simultaneously to explore the sensitivity to these performance parameters resulting in an increase in the difference between maximum and minimum volume which implies a decrease in the value of total flexibility, as shown in Fig 1. The total flexibility was increased by volume flexibility, and no other flexibility improvements were needed. However, an additional volume was required to minimize $\left(\mathrm{V}_{\max }-\mathrm{V}_{\min }\right)$ the difference between $\mathrm{V}_{\max }$ and $\mathrm{V}_{\min }$ and improving the inventory level to ensure better customer service with a higher flexibility performance parameter. Sensitivity analysis depends on i) Understanding the customer and business uncertainty: the player has to understand the customer needs for each targeted segment and the uncertainty these needs impose on the supply chain. ii) Understanding the business capabilities: the player has to understand what its supply chain is designed to do well. iii) Matching strategic fit as presented in Figure 1. To restructure the supply chain to support the competitive strategy: Authentification from the supplier allows customers to 
assume the supplier will meet product quality and service requirements. This Authentification can either be companies designed and administered, or they can be internationally recognized using standard programs like the ISO 9000 / ISO 14000 series of certification ${ }^{30}$. b) Inventory uncertainties define all raw materials, work in process, and finished goods within a supply chain. It is a major source of cost in a supply chain and has a huge impact on responsiveness ${ }^{23}$. i) Average inventory -the average amount of inventory carried. Average inventory should be measured in units, days of demand and financial value. ii) Seasonal inventory- the amount of both cycle and safety inventory that is purchased solely due to seasonal changes in demand. c) Fill rate (order/case)-the fraction of order/demand that was met on time from inventory. It should not be averaged over time but over a specified number of units of demand (i.e. every thousand, million etc). This means that an inventory turnover leads to a decrease in average inventory levels and increase in annual sales ${ }^{11}$. The highest inventory turnover ratio has a high level of liquidity; smaller risk of obsolescence and reduced investment in industry. On the other hand, low inventory level increases the risk of lost sales.

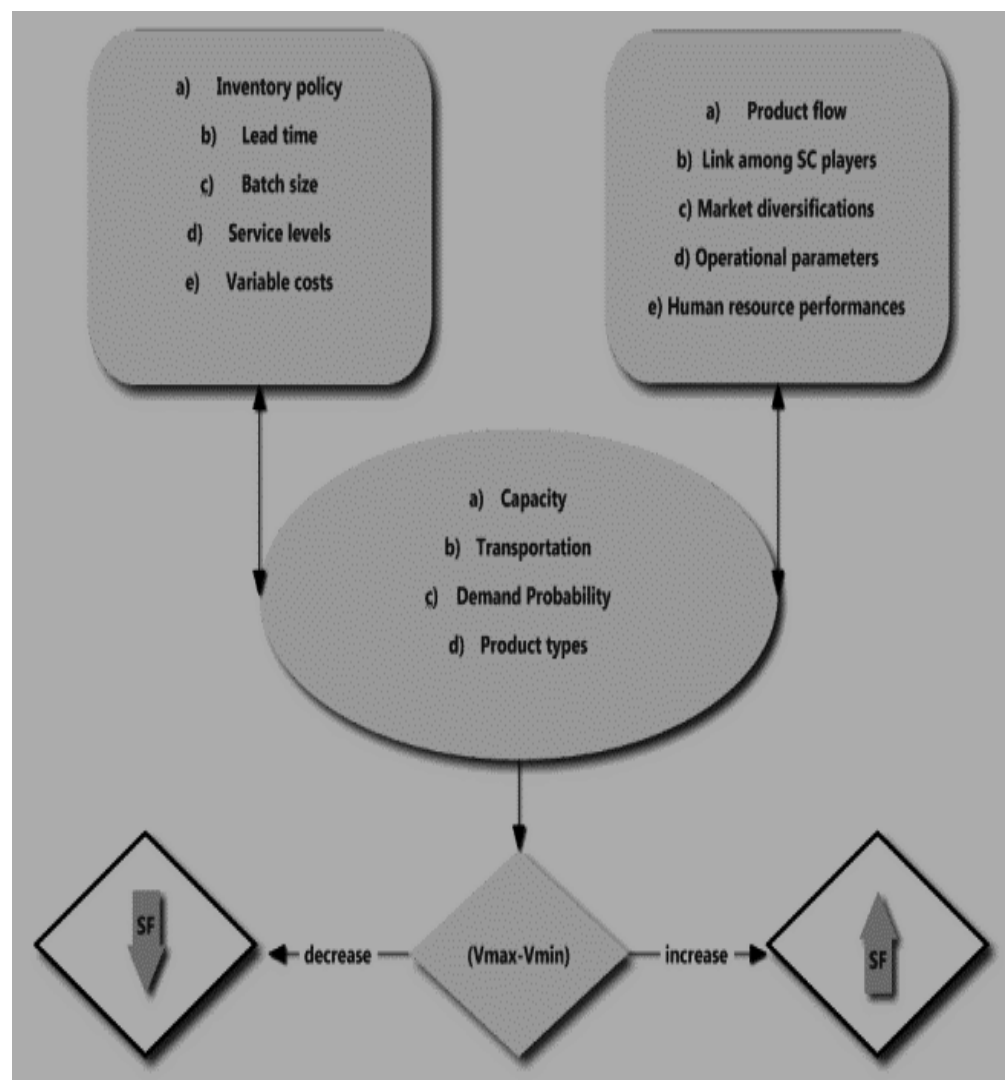

Figure 1: $\left(\mathrm{V}_{\max }-\mathrm{V}_{\min }\right) \mathrm{Vs}$. Total $S F$ with $S C$ Players

Loss of sales results in money in the competitor's account, thereby improving cash flow, and it leads to a hedge factor i.e. to carry more items and more inventories than is necessary; further factor i.e., an overestimating sales forecast with inadequate market research and intelligence ${ }^{3}$.

The fundamental trade-off that managers face when making supply chain decisions includes the cost of the number, location, capacity, the type of efficiency/net income, the level of responsiveness and the facilities provided to the customers. The trade-off defined in the inventory driver is between the responsiveness that results from more inventory and the efficiency that results from less inventory. Overall trade-off decisions should be made with the objective of increasing total profits. This indicates an understanding of the cost of the structure for performing a supply chain activity and the value this brings to the business decision. Strategies such as everyday low pricing and increasing the number of items may foster stable demand that allows for efficiency in the supply chain. Differential pricing can be used to attract customers with varying needs, as long as the strategy helps either to increase market share, and revenues or shrink costs. 


\section{Link measurements}

Evaluation of links $i j$ and $j k$ with respect to supply chain flexibilities $(S F)$ : Let us consider existing setting six links (i.e., 12, 13, 21, 23, 31, 32), 7 links, 8 links, 9 links for $i j$, and $j k$ to compare the output. Then we present $(i j+j k)$ for delivery flexibility vs. SC links, logistic flexibility vs. SC links, market flexibility vs. SC links, mix flexibility vs. SC links, operational flexibility vs. SC links, organizational flexibility vs. SC links, product flexibility vs. SC links and volume flexibility vs. SC links in Fig 2, Fig 3, Fig 4, Fig 5, Fig 6, Fig 7, Fig 8, Fig 9 respectively. Another graph is also plotted for $6,7,8,9$ links from total supplier to manufacturer and manufacturer to market flexibility vs. $S C$ links i.e., $S C$ Flexibility vs. $S C$ Links inFig 10 . Finally it is compared to links with probability and weight in Fig 11 and Fig 12.

Different types of flexibilities with total $S C$ Links Delivery cost and delivery time are important to maintain excess inventory levels in supply chain lead time. For multi-national products, the transportation time can actually be the most significant component of cumulative lead time. Cumulative lead time includes the value-added production time where components are made and assembled into finished goods, the set up time within the process where these components must set for resources to work on them, and the transportation and storage time between company-owned and external locations within the supply chain. But for national products, the delivery time can be merged with logistics facilities i.e., logistic time. This is especially true for companies in the United States, Canada, Australia and Europe that source products or components from suppliers in China and Southeast Asia. The minimum time to receive a shipment of goods from a foreign supplier is about three to four weeks via an ocean-going vessel unless high-cost air transportation is used, which may not even be feasible for all types of products and materials. Depending on the destination of the shipment relative to the domestic port, internal transit of the shipment by a rail, water vessel or trucking carrier can add another 10-12 days to the lead time. Supply chain flexibility will show actual performances of real delivery time, cost etc for this system and that is why the flexibility should be optimum. Our findings were practical, and showed trial and error depending on this program. Suppliers located in developing countries can accept a better flexibility and cost ratio due to lower site costs, lower wages, low standard environmental regulations and easy accessibility to certain natural resources. They have additional strength to invest in higher capacity of financial resources due to lower production $\operatorname{costs}^{19}$. A firm does not need to invest in a high degree of flexibility to adjust supply, process and demand risk as most of the benefits are obtained at low levels of flexibility as presented in Figure 2.

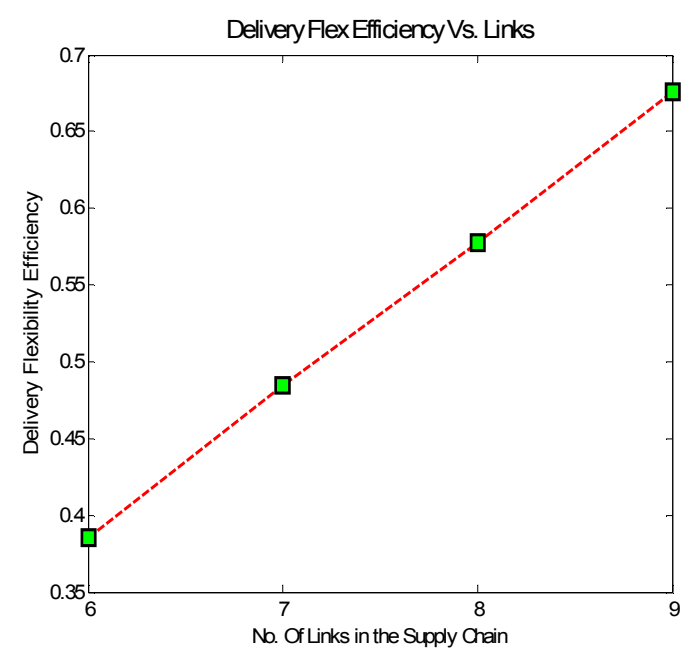

Figure 2: Delivery flexibility efficiency Vs. SC links.

Logistics is considered the most visible impact on the economic condition of society and the business functions of the modern enterprise. Companies have always the concern that a collaboration of the strengths of business partners may compensate for their own operational deficiencies and allow them to gain the capacity to expand their marketplace with customer satisfaction without expanding their costs. Customers are used to demand the higher quality products and quicker delivery at low prices. This idea establishes the importance of a supply chain system to achieve a high level of efficiency, a high level of customer service, and the ability to respond effectively to a changing environment by reconfiguring between resource and output as presented in Figure 3.

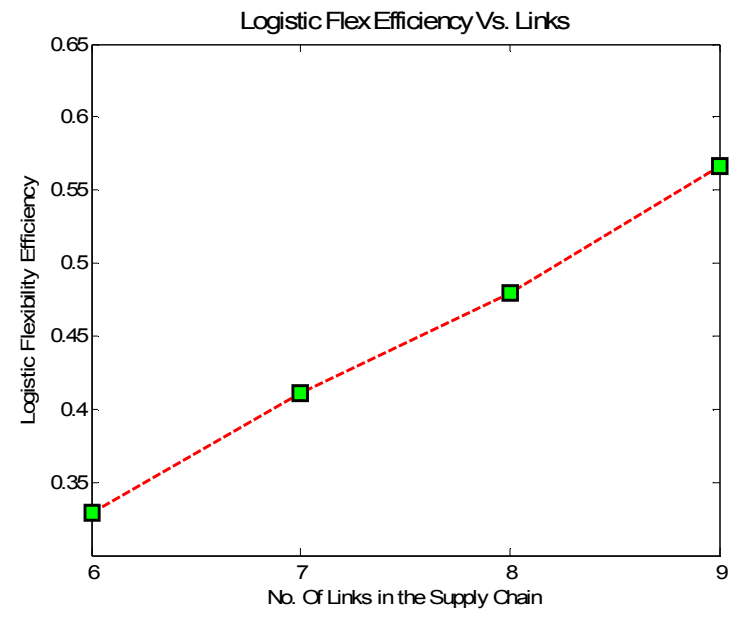

Figure 3: Logistics flexibility efficiency Vs. SC links. 
Order uncertainties and reliability of products, business goodwill and customer satisfaction dominate the supply chain flexibility. In other words, by increasing the number of observations used in the moving average, the market manager can significantly reduce the risk i.e., variability of the orders it places to the supplier. It is important that the difference between the standard deviation and coefficient of variation provide a measure of variability of customer demand. The standard deviation measures the absolute variability of customer demands, and the coefficient of variance measures variability relative to average demand. In Figure 4, the variability faced by the combined products, measured either by the standard deviation or the coefficient of variation, is much smaller than the combined variability's faced by the two individual products. The coefficient of variation tends to risk pooling, and this implies that reduction in variability allows a decrease in safety stock and therefore reduces average inventory. This means that the central storing system can optimize the inventory performance. Point of Reorder is a system-wide cost minimization procedure. If the supplier maintains a double-envelope (i.e., lead time, safety stock) safeguard system, then the market can accept risk taking decision at a reorder point. Lack of demand may lead to obsolescence which is a risk in over-stocking. It results in profit and loss for the year in the form of writing off the inventory. To achieve strategic fit, a company must tailor its supply chain flexibility to best meet the needs of different customer segments and types of product as shown in Figure 4. Aspects are the objectives or targets that decision makers expressed in terms of a specific state in space and time ${ }^{25}$.

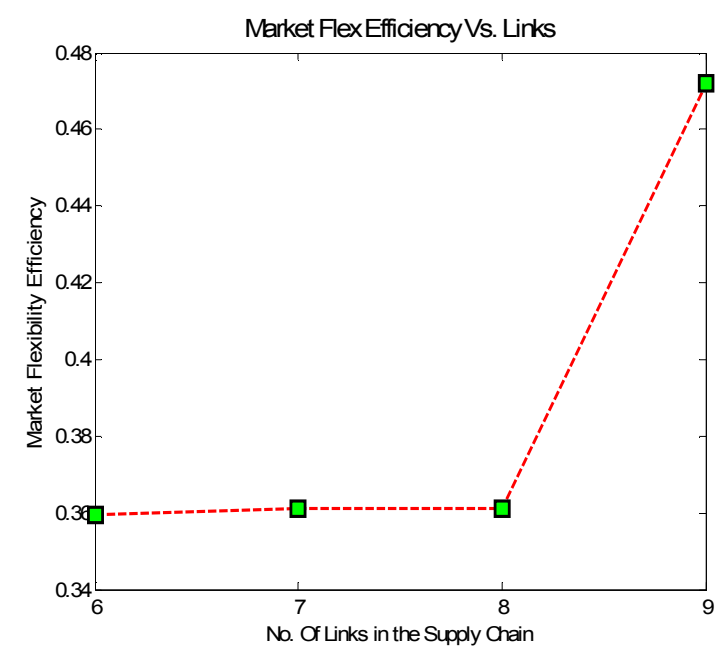

Figure 4: Market flexibility efficiency Vs. SC links.
A company may shut down either because of a lack of strategic fit or because it's overall supply chain flexibilities do not provide the capabilities to support the desired strategic fit. Failure at any process, function or element, may lead to failure of the overall chain.This study investigated the end products and some industry characteristics across the whole network related to long product life cycles and lead times, most complex and high value products. It provides an alternative means to explore the configuration, product types, planning and control flexibilities and their relationships as shown in Figure 5. Market characterization is likely to have similar feelings and ideas about a marketing mix i.e., comprising a given product or service, sold at a given price, and distributed and promoted in a certain manner. The marketing mix process in itself consists of product identification, product types, product evaluation and target product selection ${ }^{23}$. This process can allow an organization to concentrate its limited resources on the greatest opportunities to increase sales, market demand, customer satisfaction and achieve a sustainable competitive advantage. On the other hand, a fundamental issue needing rigorous attention is that customers' needs are dynamic and can induce market instability. That is why the customer values change also has to be deeply explored to avoid serious mistakes when assessing customer segments. The market mix process is critical for our supply chain flexibility modeling. The flexibility measures included in the total supply chain system have the purpose of revealing the existing levels of inventory and the duration of valueadded activities along the entire process from suppliers to customers.

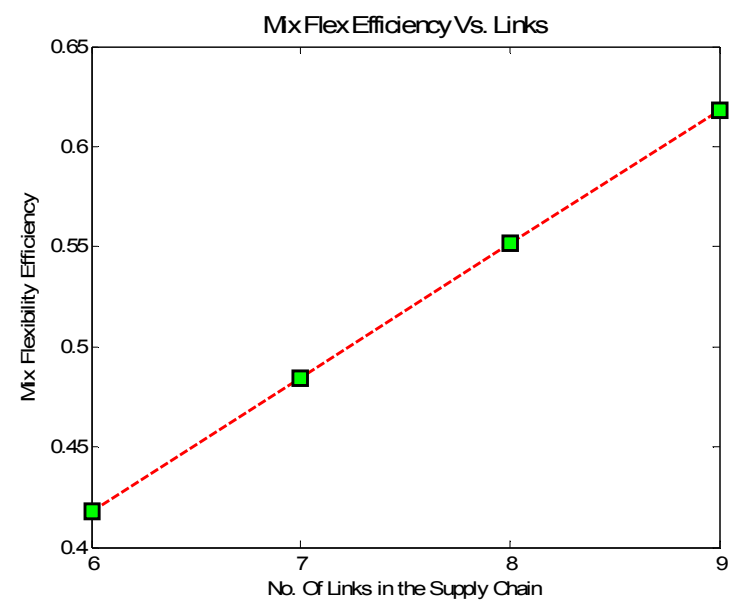

Figure 5: Mix flexibility efficiency Vs. SC links.

The inventory process represents the number of days stock is held based on average volume (units) and average daily demand (units/day). Supply chain cycle time represent the combination of delivery, 
transportation, set up and product times as presented in Figure 6. As a result a significant number of customers leave retail stores because they cannot find the products for which they are looking. This report investigation operations management focuses on two factors to explain product availability — poor assortment and poor inventory planning.

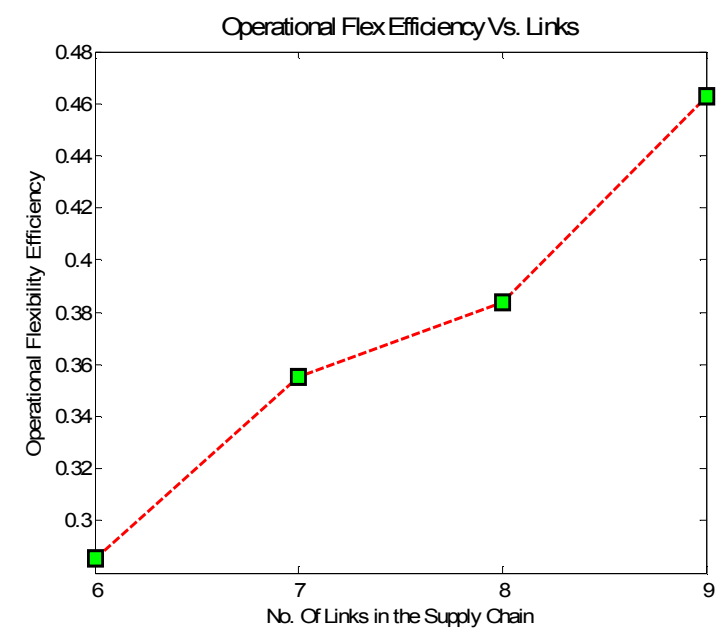

Figure 6: Operational flexibility efficiency Vs. SC links.

Operational flexibility requires appropriate network structures. This model explains capacity decisions and expected performance of networking or link configurations when time, product and utility flow are uncertain, as shown in Figure 7. Network size, product cost and market utility structures have a significant impact on the flexibility, as shown in Figure 6. It is also carried out that the sensitivity of link performance to changes in product time, cost and utility depend on market variability and correlation between product and demand while the link can be the better alternative in the probability case.Most research with several retailers highlights a third factor, poor execution, or the failure to carry-out an operational plan. We calculate that even with the application of Mat lab to select the appropriate stocking quantity and appropriate store assortment, retail customers still may face unnecessary stock outs.

When multiple customers are willing to purchase an item, the system may automatically reduce the forecast of future demand which in turn causes the retailer to stock less of it or even to drop the item from the assortment entirely ${ }^{15}$. In that situation, customers compromise retailers' service levels or retailers that rely on automated replenishment systems to manage store inventory. Execution problems affect future product availability through the distortion of historical sales and inventory data and other company strategy stored in these systems.This study examines flexibility in a network of inter-connected supply chains. It develops an understanding of the inter-organizational aspects of flexibility, their interaction with one another, human resources and their interaction with forms of flexibility within the firm as presented in Figure 8. Manpower outsourcing is certainly used to reduce the need for internal flexibility in supply between companies ${ }^{7}$.

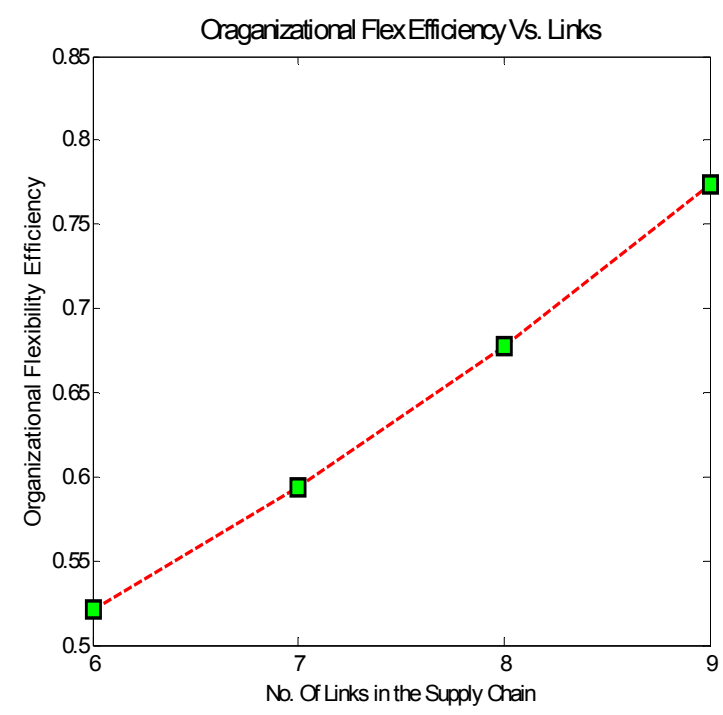

Figure 7: Organizational flexibility efficiency Vs. SC links.

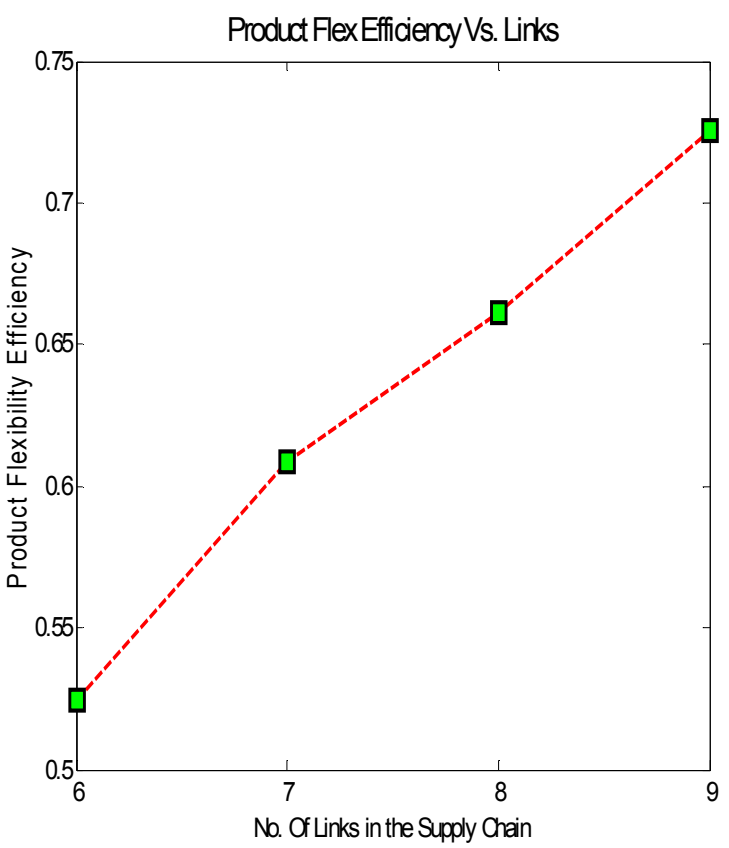

Figure 8: Product flexibility efficiency Vs. SC links. 
Volume flexibility depends on demand volatility and seasonality, forecast accuracy, production schedule uncertainty, low component commonality, just-in-time purchasing etc. A company can provide multiple sourcing, long term relationships with suppliers and inventory buffers, as shown in Figure 9. Hiring an external resource can be considered as a flexibility enabler, which has allowed companies to procure a large variety of products at different volumes.

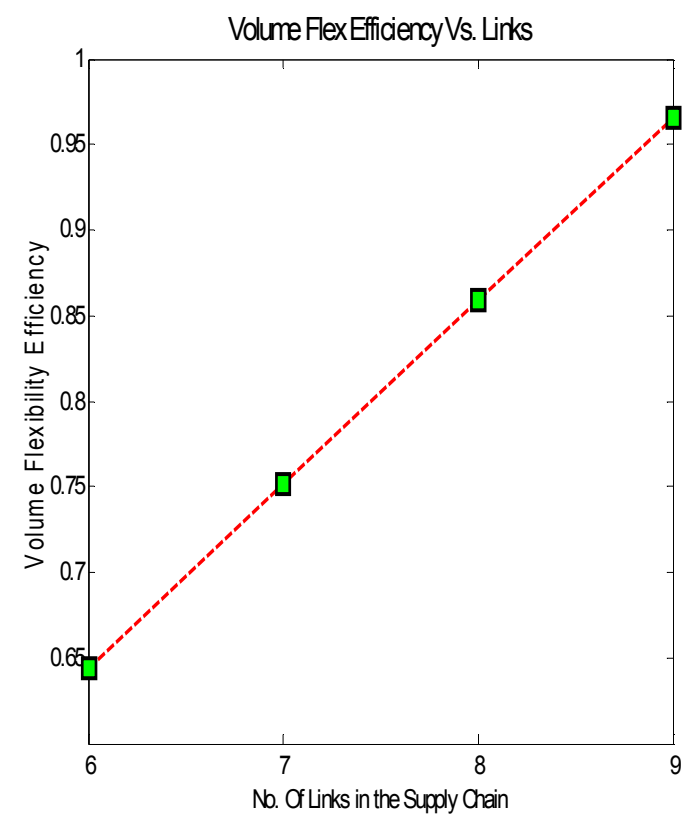

Figure 9: Volume flexibility efficiency Vs. SC links.

Flexibility could be improved by relying on relatively inexpensive human resources and low transportations costs. On the other hand, the global economy for current development has been estimated by a limiting efficiency. Optimum level flexibility could become a vital aspect to domestic companies as they may be able to achieve local benefits of flexibility easily.Application of flexibility strategies strongly depends upon product design, efficiencies of equipment, planning processes and management performances. This model is applicable to highlight relationships between flexibility and supply chain players.

Supplier to manufacturer and manufacturer to market $\boldsymbol{S C}$ Flexibility vs. $\boldsymbol{S C}$ links: There are multiple approaches to achieve supplier to manufacturer flexibility. A company may consider different combinations of resources to achieve the optimum level of supply flexibility. There is a general agreement about the impact of the integrative idea on SC flexibility, and these specific dimensions of summation should be emphasized depend on structures of the company as presented in Figure 5-10. As the obtained flexibility is low, this model should be preferable in the domestic business strategy as it's provides a marginal level of flexibility with investment 'integration' strategy. Suppliers are used to determining what the potential market is for their product or service, as well as the best ways to reach potential customers. A group supplier sharing one or more characteristics causing it to have similar product needs is called a market segment. In order to get a potential market, it must identify the characteristics of individuals likely to be interested in a particular product or service, establish how many such individuals there are, as well as study how these people behave and respond to particular needs and advertising approaches. A manufacturer can achieve rapid success in the marketplace by using a new way to divide customers into groups whose needs differ distinctly ${ }^{14}$. Market segmentation is the process of partitioning markets into these groups of potential customers with similar needs, demands, volumes and individual characteristics who are likely to exhibit similar purchase behavior. Segmentation is generally conducted using demographic, geographic, attitudinal or behavioral data. If each segment is fairly homogeneous in its needs and attitudes, it is likely to respond similarly to a given marketing strategy. This allows the companies to offer each segment a benefit package that is unmistakably tailored to meet that segment's uniquely different needs ${ }^{7}$. A competitive market segment meets all of the following criteria: supply chain players can run easily, it is distinct from other segments i.e., heterogeneity across segments; it is homogeneous within the segment i.e., exhibits common attributes; customers can take decision for product verities, it responds in a similar manner to a market stimulus, and it can be reached by a market intervention. To increase the flexibility between manufacturer and market, companies must respond to new requirements quickly without interpreting the business strategy. This model can be mapped to the business object level as shown in Figure 10. This shows the upward direction for manufacturer to market flexibility. On the other hand, adaptability reduces the cost of a dynamic supply chain, and it has no effect on flexibility. That means that the company would not invest for over capacity. To remain competitive, a company must be able to move fast, quickly adopt to change and configure their key business process to changing customer satisfaction ${ }^{23}$. Supply chain flexibility has developed a well established research domain in business management and has been relatively widely accepted in practice This model is likely to be associated with refining techniques for achieving flexibility and fusion of flexibility for managerial methods and applications. Supplier to manufacturer and manufacturer to market operating issues make challenges in designing and implementing flexible supply chains as presented in Figure 10. These 
are evolution of global supply chains, concurrence of product, design process, valuation of flexibility aspects and benefits.

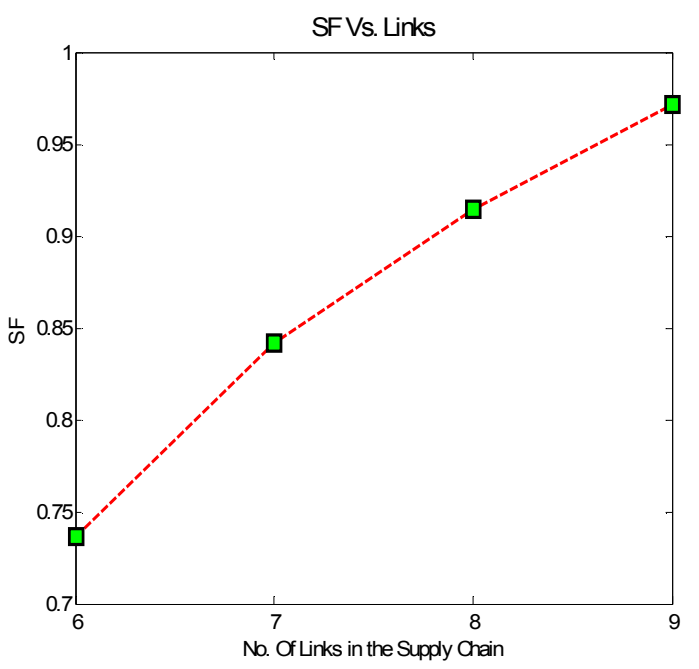

Figure 10: SC Flexibility Vs. SC Links

\section{MODEL PERCEPTIONS}

This model reviews the performance of a multi-channel supply chain system from supplier to manufacturer and manufacturer to market under demand uncertainty as presented in Fig 11. Probability with respect to the upward direction slope for supplier to manufacturer and manufacturer to market indicates that SF with communication networking is improving due to more links. The multiple set of measures reflect on time, cost, product variety, utilization, volume based efficiency and the probability of assigning customer demand by individual flexibility weight. Since the future customer requirements cannot be predicted, multi-channel manufacturing flexibility allows for a quick adaptive response to unpredictable situations ${ }^{19}$.

On the other hand, flexibility in a business system refers to consistency between the customer policies that the competitive strategy hopes to satisfy and the business capabilities that the business strategy shifts to build. The issue of decision summary is a key consideration during the supply chain performance with business strategy. All processes and functions that are part of company's value chain contribute to its failure and success $^{5}$. Uncertainty is a primary difficulty in the practical analysis of SC performance Fig 12. Probability values identify the inefficient operations and it measures the correct remedial directions ${ }^{8}$. Supply chain flexibilities do not operate in isolation; no one process or function can ensure the chain's success. Failure at any process or function, however, may lead to failure of the overall chain. Supply chain flexibility is the amount of variation in order quantity that a supplier can tolerate without letting other performance factors deteriorate. This research project carried out the measurement of supplier flexibility to consider demand quantity uncertainties (increase/decrease) and demand timing reduction uncertainty.

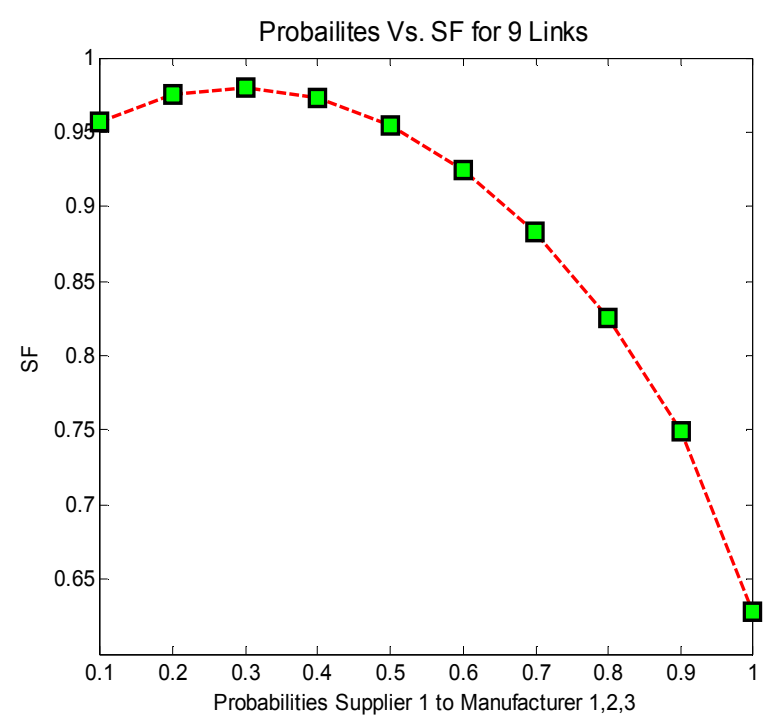

Figure 11: Probability Vs. SF for 9 links

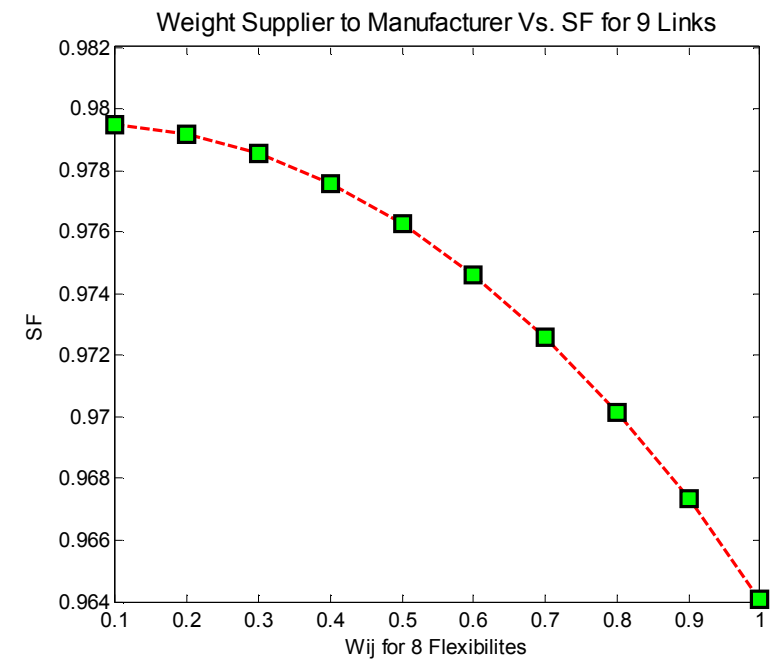

Figure 12: Weight Efficiency (Supplier to Manufacturer) Vs. SF for 9 links

This study includes the supplier selection criteria under stochastic demand conditions, i.e. to place an order below the supplier specified minimum quantity and pay a penalty or place no order and lose the sales for the current period. It has been observed that a highly flexible relationship is one in which there is little 
deterioration in the procurement price and penalties under different supply conditions: i) Expected supply cost is less sensitive to a smaller $Q_{\text {lost }}$, ii) Optimal value of lost sales $\left(\mathrm{Q}^{*}{ }_{\text {lost }}\right)$ is the inflexion point of the lost sales penalty and the quantity penalty, iii) In case of normally distributed demand, a decision to set $\mathrm{Q}_{\text {lost }}>\mathrm{Q}^{*}{ }_{\text {lost }}$ implies a steep increase in the supply cost, iv) Considering multiple supply proposal and negotiation strategy, minimum quantity is an upfront capital investment for a buyer, v) Flexibility and adaptability mechanisms are effective for improving the performance of buyer-supplier relationships which is subject to uncertainties, vi) Collaborative supply chain is more effective for mitigating supply chain risks. Finally, this study is intended to support and complement of a comprehensive selection process of suppliers and negotiation in an optimal investment for a stochastic demand.

\section{CONCLUSIONS}

The increase in globalization of the business in the performance of supply chain flexibility has made it more difficult to execute business strategies. Increasing component variety, decreasing component life cycle, and demanding customers with global competition make business strategies more difficult, as these factors can motivate decision performance. On the other hand, increasing the number of facilities and decreasing the response time, uncertainty and transportation cost leads to a higher inventory and facility cost. Uncertainty is inherent in every chain element: customer demand can never be forecast exactly; travel times will never be certain; and machines and vehicles will break down ${ }^{22}$.

i) The concept of flexibility is an application of the supply chain. A true flexible buyer-supplier relationship can be obtained when a collaborative relationship exists in which information is shared continuously. The benefits of this strong collaboration are not only cost-effective but also go beyond a translated larger flexibility in the buyer-supplier relationship. The relationship includes dimensions of supply chain flexibility and examines their relationships with business uncertainty, overall performances and functional strategies.

ii) The modeling of supply chain flexibility and its impacts on multiple entity flows are important for the level of flexibility to attain a given lead time performance and for the designers and managers of flexible supply chain systems to arrive at a judicious class. So, modeling of supply chain flexibility is a crucial need for every aspect as a mechanism to maintain a competitive position in domestic markets as well as global strategies.

iii) This is a flexibility decision making model. Performance of the entire supply chain can significantly improve if the entire chain is designed with flexible components. It is easy to recognize the importance of flexibility by increasing the competitiveness to satisfy the customer demand with less cost and shorter time.

iv) This model is a benchmark set of supply chain instances and it would improve the modeling and analysis being performed by the academician, researcher and practitioner of supply chain communities in providing thresholds for the comparison of different models, methodologies and applications.

v) Networking is an important factor for SCM. Supply chain flexibility (SF) is directly proportional to number of links. At the saturated situation, input (flexibility efficiency) is increasing more but SF seems to be constant. This model can help enterprises evaluate the responsiveness and attractiveness of their product to customer demand, which can define cumulative output in a global market.

\section{RECOMMENDATIONS}

This effort is a proof of concept study, and in many situations we may never know the networks of supply chain because of their dynamic nature and lack of information. Supplier qualification and training, resources and information sharing have significant implications for supply management policies in any firm, but particularly at different stages of maturity with networking. Further research has to provide evidence on the specific factors that determine flexibility as described in the literature review. It has to be determined how flexibility deals with external market disruptions and meets demand volatility with the aspects of a longer term and strategic perspective.

i) Flexibility should incorporate suppliers and channel members into flexibility analysis and measurement of the model of SCM system.

ii) It should address how companies with flexible ordering policies can use alternate models of demand with multi-channel strategy.

iii) It should consider how flexibility counters uncertainty in the supply chain element and the impact of disruptions for supply shortages on the market valuation.

iv) Concurrent product and process design with regard to flexibility requirements is an important research area. It is expected that 
through these expositions of theoretical and experimental solutions to supply chain flexibility analysis, this model will contribute in estimate the total performance criteria to provide a critical solution to the problem of flexibility in multi-national business firms.

v) Future research work should incorporate the relationship between supply chain flexibility and overall firm performance in a variety of market settings to confirm global flexibility.

\section{REFERENCES}

1. Leslie K. Duclos, R. J. (2003). A conceptual model of supply chain flexibility. Industrial management \& data systems , 446-456.

2. Grigore, S. D. (n.d.). Supply chain flexibility. Romanian economic and business review, Vol. 2, No. $1,66-70$.

3. Sanchoy K. das, L. A.-M. (2003). Modeling the flexibility of order quantities and lead-times in supply chains. Int. J. Production Economics 85 , 171-181.

4. Zhiying Liao, J. R. (2007). A multi-objective supplier selection model under stochastic demand conditions. Int. J. Production Economics 105 , 150159.

5. H.R.Choi, H. Y. (2000). A sales agent for part manufacturers. VMSA, decision support system 28(4), 333-346.

6. H.K. Chan, F. C. (2010). Comparative study of adaptability and flexibility in distributed manufacturing supply chains. Decision support systems $48,331-341$.

7. Christopher Tang, B. T. (2008). The power of flexibility for mitigating supply chain risks. Int. J. Production Economics , 12-27.

8. Sethi, A. S. (1990). Flexibility in manufacturing. $A$ survey international journal of flexible manufacturing systems, 2 , 289-328.

9. Saadettin Erhan Kesen, A. K. (2010). Evaluating supply chain flexibility with order quantity constrains and lost sales. Int. J. production economics $126,181-188$.

10. Abrahamsson, M., Aldin, N., Stahre, F. (2003), Logistics platforms for improved strategic flexibility. International Journal of Logistics Research and applications, 6(3), 85-106.

11. Benita, M. Beamon. (1999), Measuring Supply Chain Performance, International Journal of Operations and Production Management, 19(3), 275-292.

12. Davis, T. (1993), Effective Supply Chain Management, Management Review, 8, 35-46.

13. E.T. Tachizawa\& Cristina G.T. (2007) Drivers and Sources of Supply flexibility: An exploratory Study, International Journal of Operations \& Production Economics, 27(10), 1115-1136.

14. Lee, H.,Whang, S. (2000), Information sharing in a supply chain, International Journal of Technology Management, 20 (4), 373-387.

15. Pujawan, N. (2004), Assessing supply chain flexibility: a conceptual framework and a case study, International Journal of Integrated Supply Management, 1(1), 79-97.

16. R.R. Lummus, R.J. Vokurka., L.K.Duclos. (2005) Delphi study on supply chain flexibility, International Journal of Production Research, 43(13), 2687-2708.

17. Sanchoy K. Das., Layek Abdel-Malek. (2003) Modeling the Flexibility of Order Quantities and Lead-times in supply chains. International Journal of Production Economics, 23(1), 171-181.

18. SezerUlkij., Glen M. Schmidt., (2011) Matching Product Architecture and Supply Chain Design, Production and Operations Management, 20(1), 16-31.

19. Shawnce Vickery., Roger Calantone., Cornelia Droge. (1999), Supply Chain Management: An empirical study, Journal of Supply Chain Management. 35, 3.

20. Wahab, M.I.M., S.J. Stoyan. (2008), A dynamic approach to measure machine and routing flexibilities of manufacturing systems, International Journal of Production Economics, $113,895-913$.

21. Wathne, K.H., Heide, J.B. (2004), Relationship governance in a supply chain network, Journal of marketing, 68 (January), 73-89. 
22. Tsubone, H. Horikawa, M. (1999), Impact of various flexibility types in a hybrid fabrication / assembly production system, International Journal of Production Economics, 60-61, 117-123.

23. Benita, M. Beamon.(1999),Measuring Supply Chain Performance, International Journal of Operations and Production Management, 19(3), 275-292.

24. Chase, R.B., Jacobes, F.R.,Aquilano,N.J.(2004), Operations Management for Competitive Advantage, p.17, Irwin/ McGrawHill: Boston, MA.

25. Gosling, J.(2009),Naim, M. (Eds.), European Operations Management Association (EuroMA), Gothendurg, Sweden, 14-17 June.

26. Ian Sadler.(2007)Logistics and Supply Chain Integration, Journal of manufacturing technology management, 16(8),890-908.

27. Wadhwa, S. Rao, K.S. (2000), Flexibility: An emerging Meta-competence for managing high technology, International Journal of Technology Management,19(7/8), 820-845.

28. Virolainen, V.M. (1998), A survey of procurement strategy development in industrial companies, International Journal of Production Economics, 56/57, 677-688.

29. Lee, H.L.(2004). A triple a supply chain in Harvard Business Review, 82(10).102-112.

30. Lummus, R.R., Vokurka, R.J.,Alber, K.L.(1998), Strategic supply chain planning, International Production and Inventory Management Journal, 39(3), 49-58.

31. Wadhwa, S. Rao, K.S. (2000), Flexibility: An emerging Meta-competence for managing high technology, International Journal of Technology Management, 19(7/8), 820-845.

32. Jin, B. (2004), Achieving an optimal global versus domestic sourcing balance under demand uncertainty, International Journal of Operations and Production Management, 24(12), 1292-1306. 